OPEN ACCESS

Edited by:

Robert Hetland,

Texas A\&M University, United States

Reviewed by:

J. German Rodriguez,

Technological Center Expert in Marine and Food Innovation (AZTI), Spain

Edward B. Overton, Louisiana State University,

United States

*Correspondence:

Arne R. Diercks

arne.diercks@usm.edu

Isabel C. Romero

isabelromero@usf.edu

Specialty section:

This article was submitted to

Marine Pollution,

a section of the journal

Frontiers in Marine Science

Received: 16 November 2020

Accepted: 25 May 2021

Published: 01 July 2021

Citation:

Diercks AR, Romero IC, Larson RA, Schwing P, Harris A, Bosman S, Chanton JP and Brooks G (2021) Resuspension, Redistribution, and Deposition of Oil-Residues to Offshore Depocenters After the Deepwater Horizon Oil Spill.

Front. Mar. Sci. 8:630183

doi: 10.3389/fmars.2021.630183

\section{Resuspension, Redistribution, and Deposition of Oil-Residues to Offshore Depocenters After the Deepwater Horizon Oil Spill}

\author{
Arne R. Diercks 1*, Isabel C. Romero ${ }^{2 *}$, Rebekka A. Larson ${ }^{3}$, Patrick Schwing ${ }^{2,3}$, \\ Austin Harris ${ }^{1}$, Samantha Bosman ${ }^{4}$, Jeffrey P. Chanton ${ }^{4}$ and Gregg Brooks ${ }^{3}$ \\ ${ }^{1}$ Division of Marine Science, School of Ocean Science and Engineering, The University of Southern Mississippi, Hattiesburg, \\ MS, United States, ${ }^{2}$ College of Marine Science, University of South Florida, St. Petersburg, FL, United States, ${ }^{3}$ Department \\ of Marine Science, Eckerd College, St. Petersburg, FL, United States, ${ }^{4}$ Department of Earth Ocean and Atmospheric \\ Science, Florida State University, Tallahassee, FL, United States
}

The focus of this study was to determine the long-term fate of oil-residues from the 2010 Deepwater Horizon (DwH) oil spill due to remobilization, transport, and redistribution of oil residue contaminated sediments to down-slope depocenters following initial deposition on the seafloor. We characterized hydrocarbon residues, bulk sediment organic matter, ease of resuspension, sedimentology, and accumulation rates to define distribution patterns in a $14,300 \mathrm{~km}^{2}$ area southeast of the $\mathrm{DwH}$ wellhead $(1,500$ to 2,600 $\mathrm{m}$ water depth). Oil-residues from the $\mathrm{DwH}$ were detected at low concentrations in $62 \%$ of the studied sites at specific sediment layers, denoting episodic deposition of oil-residues during 2010-2014 and 2015-2018 periods. DwH oil residues exhibited a spatial distribution pattern that did not correspond with the distribution of the surface oil slick, subsurface plume or original seafloor spatial expression. Three different regions were apparent in the overall study area and distinguished by the episodic nature of sediment accumulation, the ease of sediment resuspension, the timing of oil-residue deposition, carbon content and isotopic composition and foram fracturing extent. These data indicate that resuspension and down-slope redistribution of oil-residues occurred in the years following the $\mathrm{DwH}$ event and must be considered in determining the fate of the spilled oil deposited on the seafloor.

Keywords: resuspension, hydrocarbons, accumulation rates, radiogeochemistry, geochronology, Lead-210, radiocarbon, deep sea Gulf of Mexico

\section{INTRODUCTION}

A large percentage of the oil released during the 2010 Deepwater Horizon (DwH) spill in the northern Gulf of Mexico (GoM) was either chemically or naturally dispersed (Lehr et al., 2010; Lubchenco et al., 2012) and/or settled to the seafloor associated with the Marine Oil Snow Sedimentation and Flocculent Accumulation event (MOSSFA) (Passow et al., 2013; Daly et al., 2016). MOSSFA consisted of oil residues mixed with organic and inorganic particles, including bacteria, phytoplankton, microzooplankton, zooplankton fecal pellets, detritus, and terrestrially derived lithogenic particles (Daly et al., 2020). The observed MOSSFA event transported a 
significant portion of the released oil to the seafloor in a short time (Passow et al., 2012; Joye et al., 2013; Ziervogel et al., 2016; Romero et al., 2017). Increased short-term (months) sedimentation rates reflected the rapid transport of sediments to the seafloor associated with the MOSSFA event (Brooks et al., 2015; Romero et al., 2015, 2017; Yan et al., 2016; Larson et al., 2018). Layers of detectable oil-contaminated sediment were deposited on the seafloor directly below the extent of the surface slick or under the southwest deep sea plume (Valentine et al., 2014; Brooks et al., 2015; Chanton et al., 2015; Romero et al., 2015, 2017; Larson et al., 2018). However, a sampling bias toward seafloor locations under the surface slicks and the deep plumes (Camilli et al., 2010; Diercks et al., 2010) exists, and sediments were sampled at only few of the locations outside these areas (Schwing et al., 2017).

Lehr et al. (2010) estimated that $11-30 \%$ of the released oil was unaccounted for or listed as "other" (i.e., difficult to measure/quantify including oil on beaches, in tar balls, in shallow subsurface mats, and deep-sea sediments). While the sedimentation of oil is often discussed, for example, Jernelöv and Lindén (1981) speculated that $25 \%$ of the 475,000 metric tons of oil released from the 1979 Ixtoc spill went to the seafloor, its role has never properly been assessed. Valentine et al. (2014) estimated that 1.8 to $14.4 \%$ of the DwH oil remained in subsurface plumes and was deposited on the seafloor around the wellhead, while Chanton et al. (2015) indicated that between 0.5 and $9.1 \%$ of the total oil released by the DwH spill reached the seafloor in continental shelf to deep-sea areas. Covering a larger area from the coast to deep-sea, Romero et al. (2017) using 158 hydrocarbon compounds calculated that $21 \pm 10 \%$ of the total oil released and not recovered by the DwH spill was deposited on $\sim 110,000 \mathrm{~km}^{2}$ of the seafloor, in which $32,648 \mathrm{~km}^{2}$ corresponded to offshore deep-sea areas. Similarly, Schwing et al. (2017) indicated that increased sediment deposition occurred throughout an area of $12,805-35,425 \mathrm{~km}^{2}$ in deep-sea sediments. In contrast, the surface oil slick covered a more extensive area, from 141,581 km for 1 day, to $42,023 \mathrm{~km}^{2}$ for 10 days and $14,357 \mathrm{~km}^{2}$ for 30 days (Crowsey, 2013). All together, these studies define the spatial footprint of the MOSSFA event, including areas that lacked detectable oil. However, up to date, no study has addressed the potential role of post-depositional processes in changing the initial distribution of MOSSFA in sediments.

Natural heterogeneity of bottom topography and circulation processes are key drivers in redistributing materials to deeper areas in the GoM by erosion, transport and deposition of contaminated sediments beyond the surface extent of the once existing oil surface slick or the subsurface plumes(s). The northern GoM deep seafloor depositional environment is of high diversity resulting in non-homogeneous distribution and burial of material arriving from the overlying water column. Seafloor sedimentation is affected by currents, bottom morphology, and physical forcing events of different temporal and spatial scales that rework deposited material within the Bottom Nepheloid Layer (BNL) (Lampitt, 1985; Turnewitsch et al., 2004, 2013, 2017).

Large-scale gravity flow events (e.g., turbidity currents) can move large quantities of sediment downslope, regardless of overlying currents, following gravitational pull and the path of least resistance on the seafloor. Mobilized sediments flow along pathways based on the highly variable seafloor morphology, with its hills, slopes and channels, allowing for erosion and deposition beyond the spatial extent of the once existing oil slick or subsurface plumes(s). These processes can lead to a redistribution of sediments and potential sediment focusing in deep-sea depocenters that were targeted in this study. Previous studies in the deep eastern Gulf of Mexico show redistribution of sediments by gravity flow processes to be common, specifically on the Mississippi Fan, adjacent to our study area (Coleman et al., 1986; Cremer and Stow, 1986; Normark et al., 1986; Stow et al., 1986; Thayer et al., 1986). Based primarily on sedimentary structures, dominant processes are interpreted to be low-density with fine-grained turbidity currents deposited very rapidly in channel and overbank settings, as well as slides and slumps. Turbidity currents likely occur up to 5-6 times per year, possibly in pulses, and accumulation lasts hours to days before overlying sediments are deposited, all of which may explain the lack of extensive bioturbation, exceptionally high rates of accumulation, and excellent preservation (Coleman et al., 1986).

We tested the hypothesis that DwH impacted sediments that were initially deposited on the seafloor beneath the surface oil slicks and plumes, were subsequently remobilized and transported down-slope in the years following the DwH spill. Sediment accumulation on the seafloor is not a simple one-time process during which material settles to the seafloor, and not all the material accumulates (i.e., is buried) at the location of the initial deposition. Sediment cores were collected to determine if the sediments at the coring sites were impacted by the $\mathrm{DwH}$ spill. The distribution of contaminated sediments mapped in the years following the spill is likely an underestimation (e.g., Valentine et al., 2014; Chanton et al., 2015; Romero et al., 2017) due to resuspension and redistribution processes (e.g., Diercks et al., 2018) following their initial deposition on the seafloor. Characterization of the spatial distribution of oil-contaminated sediments along the continental slope at depths $>1,500 \mathrm{~m}$ is critical for understanding the long-term fate of the spilled oil from the $\mathrm{DwH}$ in deep-sea areas.

\section{MATERIALS AND METHODS}

\section{Watershed Modeling and Site Selection}

Based on the recently published high resolution bathymetry by Kramer and Shedd (2017), a high resolution watershed drainage model was created, restricted to vertical bin resolution of $5 \mathrm{~m}$ to guide the site selection for in situ sediment coring. Stream lengths of $<1 \mathrm{~km}$ were excluded in the graphic representation of the model data (Figure 1) to allow for better visibility in the larger scale maps of the study area. Sampling sites were determined based on the geomorphology of the seafloor, slope angle and the flow direction from the watershed drainage model. Selection of sampling sites was based primarily on areas on the seafloor where we expected sediments to be remobilized from and where they eventually would be deposited to (i.e., depocenters). We classified these areas into channels, lee 


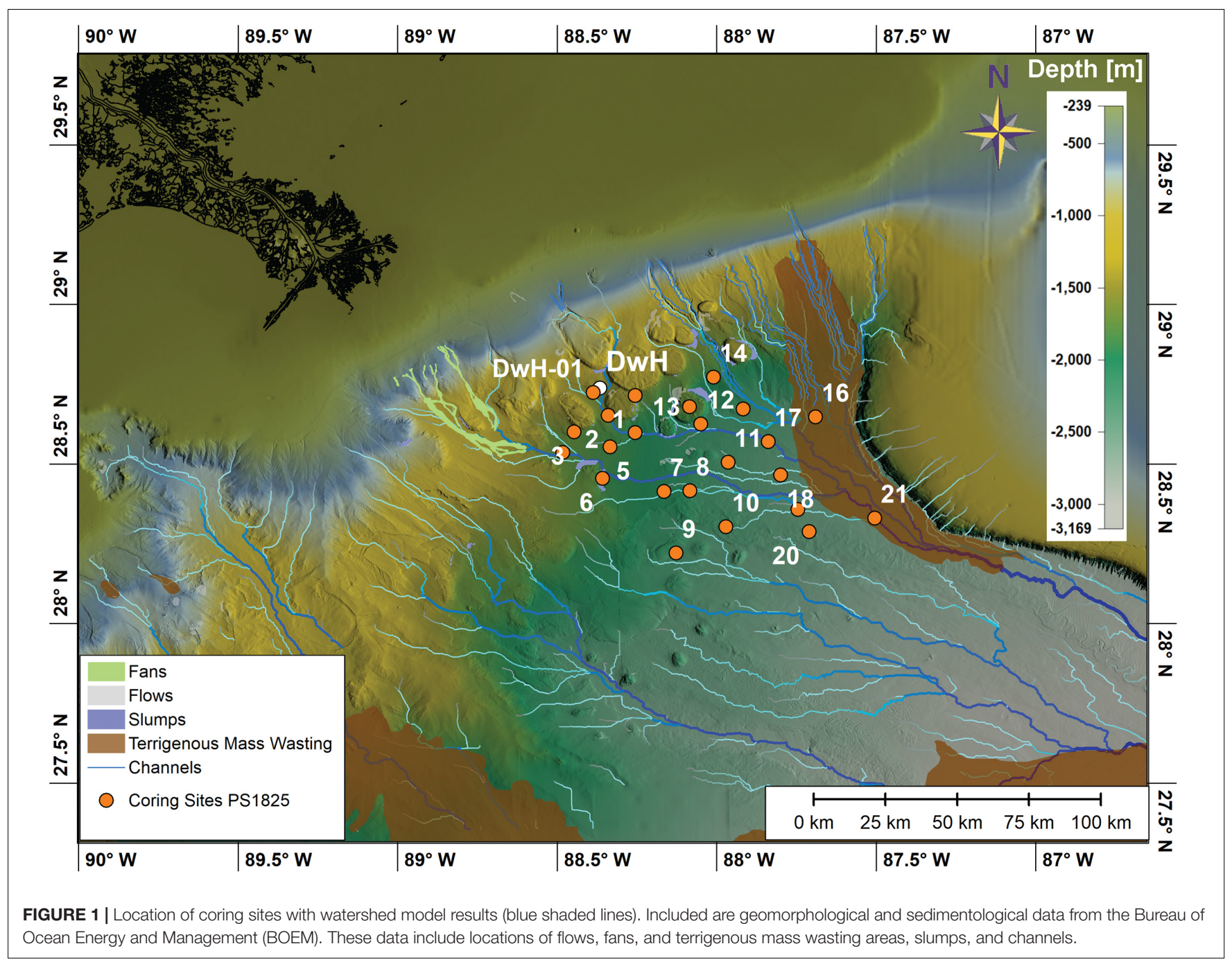

depocenters, and bathymetric depressions (Table 1). Channels can be erosional and/or depositional in nature. Channels act as conduits for the downslope mass movement of sediments, and although commonly erosional when active, are most often depositional over the long term. Lee depocenters are located in the lee or "down-slope shadow" of morphologic highs. They become centers of deposition as the energy level of the transport mechanism decreases in the lee of the morphological high (Turnewitsch et al., 2013). Similar depositional conditions are expected over large flat areas which are characterized as low energy environments. Isolated valleys or bathymetric depressions, valleys surrounded by morphological highs isolating them from any horizontal gravitational outflow, are similar in that the energy level tends to decrease in these features, which promotes deposition

\section{Collection of Sediment Cores}

Sediment samples were collected during the RV Point Sur cruise 18-25 in May of 2018, using a MC-800 multi corer $(10 \mathrm{~cm}$ diameter $\times 70 \mathrm{~cm}$ long tubes $)$ at the studied sites
(Figure 1 and Table 1). The Ocean Instruments MC-800 multi corer collected eight cores simultaneously and each core was used for a separate analysis (e.g., one core for bulk isotope analyses, one for short-lived radioisotope geochronology and sedimentology, one for XRF scanning, two for flume studies, one for hydrocarbon biomarkers, one for foraminiferal analyses, and one archived).

\section{Sediment Resuspension Flume}

To analyze resuspension behavior of the core samples, a linear closed loop flume was constructed. The resuspension flume (Supplementary Figure 1) was designed based on the Sedflume published by Borrowman et al. (2006). A $95 \mathrm{~cm}$ long $15 \mathrm{~cm}$ wide and $5 \mathrm{~cm}$ high closed channel was connected to a reservoir, through $5 \mathrm{~cm}$ diameter PVC pipes. In the upstream section of the flume, a DIGITEN model FL-1608 Hall Sensor flowmeter was installed in line before the flow diverter that converted the $5 \mathrm{~cm}$ PVC pipe into the rectangular test section of the flume. This flow diverter together with $147 \mathrm{~cm}$ of rectangular channel before the core insertion point allowed for full development of turbulent 
TABLE 1 | Table of morphological classification and flume experiment data with surface sediment properties.

\begin{tabular}{|c|c|c|c|c|c|c|c|c|c|c|c|c|}
\hline Site & $\begin{array}{l}\text { Latitude } \\
\qquad(\mathrm{N})\end{array}$ & $\begin{array}{l}\text { Longitude } \\
\text { (W) }\end{array}$ & $\begin{array}{l}\text { Depth } \\
\text { (m) }\end{array}$ & Depocenter type & $\begin{array}{c}\text { Sediment } \\
\text { structure } \\
\text { type }\end{array}$ & $\begin{array}{c}\text { Intervals } \\
\text { with } \\
\text { structures } \\
\text { (cm) }\end{array}$ & Region & $\begin{array}{c}\text { Flow } \\
\text { speed at } \\
\text { initial } \\
\text { erosion } \\
\left(\mathrm{cm} \mathrm{s}^{-1}\right)\end{array}$ & $\begin{array}{c}\text { Total } \\
\text { volume } \\
\text { eroded } \\
\left(\mathrm{cm}^{3}\right)\end{array}$ & $\begin{array}{c}\text { Average } \\
\text { particle } \\
\text { size }\left(\mathrm{mm}^{2}\right)\end{array}$ & $\begin{array}{c}\text { Flow } \\
\text { speed of } \\
\text { first peak } \\
\text { in } \\
\text { sediment } \\
\text { volume } \\
\left(\mathrm{cm} \mathrm{s}^{-1}\right)\end{array}$ & $\begin{array}{c}\text { Volume } \\
\text { eroded } \\
\text { before } \\
\text { first peak } \\
\left(\mathrm{cm}^{3}\right)\end{array}$ \\
\hline 1 & 28.7143 & -88.2552 & 1,703 & Channel & A & & 1 & ND & ND & ND & ND & ND \\
\hline 2 & 28.6526 & -88.3393 & 1,750 & Lee & A & & 1 & ND & ND & ND & ND & ND \\
\hline 3 & 28.6007 & -88.4467 & 1,725 & Lee & $A$ & & 1 & ND & ND & ND & ND & ND \\
\hline 4 & 28.5365 & -88.4817 & 1,743 & Lee & A & & 1 & 4.57 & 26.52 & 0.45 & 13.72 & 10.82 \\
\hline 5 & 28.5473 & -88.336 & 1,890 & Lee & A & & 2 & 1.14 & 20.41 & 0.63 & 8 & 0.03 \\
\hline 6 & 28.4558 & -88.3568 & 1,910 & Lee & $A$ and $B$ & & 2 & 4.57 & 56.34 & 0.51 & 16 & 43.66 \\
\hline 7 & 28.4143 & -88.1656 & 2,064 & Depression & $A$ and $B$ & & 3 & 1.14 & 34.37 & 0.45 & 11.43 & 16.67 \\
\hline 8 & 28.4205 & -88.0844 & 2,170 & Channel & A & $0-23$ & 3 & 3.43 & 11.93 & 0.45 & 14.86 & 0.26 \\
\hline 9 & 28.221 & -88.1269 & 2,272 & Depression & A & $0-25$ & 3 & 3.43 & 5.63 & 0.39 & 5.72 & 0.02 \\
\hline 10 & 28.3023 & -87.9702 & 2,290 & Channel & $\begin{array}{c}A \text { and } B \\
A\end{array}$ & $\begin{array}{c}0-5 \\
15-20\end{array}$ & $\begin{array}{l}3 \\
3\end{array}$ & 2.29 & 21.01 & 0.39 & 6.86 & 0.05 \\
\hline 11 & 28.5048 & -87.964 & 2,282 & Depression & $\begin{array}{c}A \text { and } B \\
A\end{array}$ & $\begin{array}{c}0-10 \\
18-20\end{array}$ & $\begin{array}{l}3 \\
3\end{array}$ & 2.29 & 535.51 & 0.49 & 6.86 & 9.66 \\
\hline 12 & 28.6253 & -88.0489 & 2,179 & Lee & A & $0-6$ & 2 & 3.43 & 44.6 & 0.46 & 8 & 0.34 \\
\hline 13 & 28.6796 & -88.0848 & 1,763 & Depression & $A$ and $C$ & & 2 & 2.29 & 24.69 & 0.5 & 13.72 & 12.32 \\
\hline 14 & 28.7718 & -88.0096 & 1,946 & Channel & $A$ and $C$ & & 2 & 1.14 & 190.52 & 0.47 & 6.86 & 3.81 \\
\hline 15 & 28.6728 & -87.916 & 2,410 & Channel levee & A & $0-5$ & 3 & 2.29 & 72.44 & 0.44 & 12.57 & 12.84 \\
\hline 16 & 28.6473 & -87.6902 & 2,381 & $\begin{array}{c}\text { Channel } \\
\text { (confluence) }\end{array}$ & A & $0-7$ & 3 & 2.29 & 48.25 & 0.46 & 10.29 & 1.84 \\
\hline 17 & 28.57 & -87.8378 & 2,344 & Channel & $A$ & $0-7$ & 3 & 2.29 & 23.32 & 0.46 & 11.43 & 9.31 \\
\hline 18 & 28.4662 & -87.7996 & 2,393 & Channel & A & $0-7$ & 3 & 2.29 & 4.41 & 0.43 & 9.14 & 0 \\
\hline 19 & 28.3574 & -87.7451 & 2,459 & Channel & A & $0-20$ & 3 & 1.14 & 37.77 & 0.4 & 10.29 & 2.37 \\
\hline 20 & 28.2046 & -87.7103 & 2,448 & Depression/plain & & & 3 & 1.14 & 65.5 & 0.44 & 6.86 & 1.12 \\
\hline 21 & 28.3306 & -87.5042 & 2,584 & $\begin{array}{c}\text { Channel } \\
\text { (confluence) }\end{array}$ & $\mathrm{C}$ & Oct-20 & 3 & 4.57 & 18.95 & 0.42 & 16 & 6.53 \\
\hline 30 & 28.5959 & -88.2514 & 1,986 & $\begin{array}{c}\text { Depression/channel } \\
\text { (?) }\end{array}$ & $A$ & $0-25$ & 2 & 3.43 & 71.92 & 0.46 & 12.57 & 22.31 \\
\hline DwH01 & 28.7241 & -88.3872 & 1,570 & DwH wellhead & $A$ & 02-May & 1 & 1.14 & 20.24 & 0.42 & 12.57 & 8.32 \\
\hline
\end{tabular}

ND indicates no data if core tops were too disturbed or not enough multicores collected on that site to allow flume analysis.

Labels: A, sub-parallel laminae/wavy bedding; B, color banded units; C, inclined beds (Figure 2).

flow within the rectangular channel. At $147 \mathrm{~cm}$ beyond the flow diverter, a $10 \mathrm{~cm}$ diameter core opening was located at the base of the flume, allowing for insertion of the core into the flume. At the end of the rectangular section, another diverter reduced the diameter back to a $5 \mathrm{~cm}$ pipe through which the water was directed into a filtration system and the filtered, clean water was returned by the pump into the flume channel, thus creating the closed loop system.

A core extruding mechanism secured the core tube in the bottom of the flume during the test and permitted smooth controlled and undisturbed insertion of the core sediment into the flume. Cores had been collected and stored with a large amount of original seawater in the core tube overlying the sediment water interface. The flume was filled with filtered artificial salt water (salinity $\sim 35$ ) prior to each test, and drained and cleaned after each experiment. The closed loop system provided an instantaneous movement of water within the entire flume when the pump was turned on.
During each test, a Sony $4 \mathrm{k}$ camcorder, mounted $20-\mathrm{cm}$ beyond the core, with its focal point set at the center of the channel, recorded video data of calibrated particle size distribution of the material being eroded from the core top and transported down-channel. Time synchronized video footage was post processed using the GNU software FFMPEG into individual tagged image format files (TIF). For every 30 frames (video recorded at 30 frames per second), four images were extracted evenly spaced for every second of video time. Given the dimensions of the camera to the flume setup, this allowed for particles to be imaged in at least three consecutive images at the highest flow speed. Once all TIF images were extracted, they were analyzed using the Image Pro Plus ${ }^{\circledR}$ software. All images were normalized into 8-bit gray scale images. A standard area of interest (AOI) with calibrated known dimensions was extracted from the image. The AOI was saved as separate file. The next image in time was loaded normalized, had the AOI applied and saved. During the following step, the first AOI was subtracted 
from the second AOI, leaving in the resulting image only particles that had shifted (moved within the channel) in position. Every stationary object was removed in the image subtraction process. All visible particles in the resulting image were counted and grouped into 10 size bins ranging from $0.2 \mathrm{~mm}^{2}$ to $>1.8 \mathrm{~mm}^{2}$ in $0.2 \mathrm{~mm}^{2}$ steps.

\section{Core Splitting and Extrusion}

With the exception of the flume cores, sediment cores were either split longitudinally or extruded upward from the core base for sampling. Sediment cores were extruded at $2 \mathrm{~mm}$ intervals for surficial sediment $(2-10 \mathrm{~mm})$ to ensure the highest possible resolution of recently deposited sediments, and subsequently at $5 \mathrm{~mm}$ intervals to the base of the core. Cores were volumetrically extruded according to the method described in Schwing et al. (2016). One core from each deployment was split longitudinally, photographed and described visually. This included assessment of stratigraphic integrity and a variety of sedimentary structures that are indicators of down-slope transport mechanisms.

\section{Short-Lived Radioisotopes}

Short-lived radioisotope analyses were performed to provide age control and accumulation rates over the past $\sim 100$ years. Samples were analyzed for short-lived radioisotopes by gamma spectrometry on Series HPGe (High-Purity Germanium) Coaxial Planar Photon Detectors for activities of total Lead-210 $\left({ }^{210} \mathrm{~Pb}_{\text {Tot }}\right)$ at 46.5 kiloelectron volts (keV), Lead-214 $\left({ }^{214} \mathrm{~Pb}\right)$ at $295 \mathrm{keV}$ and $351 \mathrm{keV}$, Bismuth-214 ( $\left.{ }^{214} \mathrm{Bi}\right)$ at $609 \mathrm{keV}$, and total Thorium-234 $\left({ }^{234} \mathrm{Th}_{\text {Tot }}\right)$ at $63 \mathrm{keV}$. Samples were also analyzed for Cesium$137\left({ }^{137} \mathrm{Cs}\right)$ at $661 \mathrm{keV}$, and Berilium-7 $\left({ }^{7} \mathrm{Be}\right)$ at $477 \mathrm{keV}$, but these radioisotopes were below detection in all samples and therefore will not be discussed. Data were corrected for emission probability at the measured energy, counting time, sample mass, and converted to activity (disintegrations per minute per gram, $\mathrm{dpm} / \mathrm{g}$ ), using the International Atomic Energy Association (IAEA) organic standard IAEA-447 for calibration (Kitto, 1991; Larson et al., 2018).

The activities of the ${ }^{214} \mathrm{~Pb}(295 \mathrm{keV}),{ }^{214} \mathrm{~Pb}(351 \mathrm{keV})$, and ${ }^{214} \mathrm{Bi}(609 \mathrm{keV})$ were averaged as a proxy for the Radium$226\left({ }^{226} \mathrm{Ra}\right)$ activity of the sample or the "supported" Lead$210\left({ }^{210} \mathrm{~Pb}_{\text {Sup }}\right)$ that is produced in situ (Smith et al., 2002; Baskaran et al., 2014; Swarzenski, 2014). The ${ }^{210} \mathrm{~Pb}_{\text {Sup }}$ activity was subtracted from the ${ }^{210} \mathrm{~Pb}_{\text {Tot }}$ activity to calculate the "unsupported" or "excess" Lead-210 $\left({ }^{210} \mathrm{~Pb}_{x s}\right)$, which is used for dating within the last $\sim 100$ years.

The Constant Rate of Supply (CRS) algorithm was employed to assign specific ages to sedimentary intervals within the ${ }^{210} \mathrm{~Pb}_{x s}$ profile. The CRS algorithm is appropriate under conditions of varying accumulation rates (Appleby and Oldfield, 1983; Binford, 1990). Mass accumulation rates (MAR) were calculated for each data point (i.e., "date"), based upon the CRS model results. The use of MAR corrects for differential sediment compaction down core, thereby enabling a direct comparison of ${ }^{210} \mathrm{~Pb}_{x s}$ accumulation rates throughout a core (i.e., over the last $\sim 120$ years). MAR were calculated as follows:

$$
\operatorname{MAR}\left(\mathrm{g} / \mathrm{cm}^{2} / \text { year }\right)=\text { dry bulk density } \times L A R
$$

Where:

$$
\begin{aligned}
\text { Dry bulk density }\left(\mathrm{g} / \mathrm{cm}^{3}\right) & =\text { sample dry mass }(\mathrm{g}) \\
& \div \text { sample volume }\left(\mathrm{cm}^{3}\right)
\end{aligned}
$$

$$
L A R=\text { linear accumulation rate }(\mathrm{cm} / \text { year })
$$

${ }^{210} \mathrm{~Pb}_{x s}$ profiles were evaluated for the number of plateaus, the accumulation $(\mathrm{mm})$ that was associated with plateaus e.g., accumulated as a pulse events, and the \% of the total accumulation $(\mathrm{mm})$ that occurred as a pulse. To quantify the accumulation for each core from episodic sedimentation a "Pulse Index" (P.I.) was calculated with the number of plateaus contributing $15 \%$ toward the index, the $\%$ of total accumulation that occurred with pulses (plateaus) contributing $50 \%$ toward the index, and the average MAR (1950-2018) contributing 35\% toward the index (Supplementary Table 1 and Supplementary Figure 2).

\section{Sedimentology}

Sediment texture and composition analyses were conducted on extruded samples and included bulk density, grain size, and composition. One core per site was used to calculate pore water content and bulk density. Sample volume was calculated using the inner diameter of the core barrel and sampling interval (i.e., height). Samples were weighed immediately after extrusion to provide the wet mass required for determining pore water content. Each sample was then freeze-dried and weighed for dry mass to calculate dry bulk density (Binford, 1990; Appleby, 2001).

Grain size was determined by wet sieving the sample through a $63 \mu \mathrm{m}$ screen. The fine-size $(<63 \mu \mathrm{m})$ fraction was analyzed by pipette (Folk, 1965) to measure the relative percentage of silt (\%silt) and clay (\%clay). The sand-size $(>63 \mu \mathrm{m})$ fraction was volumetrically too small to analyze further and is reported here as \%sand. \%Gravel and \%sand were determined by dry sieving the $>63$ micron fraction. Carbonate content (\%carbonate) was determined by the acid leaching method according to Milliman (1974). Total organic matter (\%TOM) was determined by loss on ignition (LOI) at $550^{\circ} \mathrm{C}$ for at least $2.5 \mathrm{~h}$ (Dean, 1974). The non-carbonate and non-organic fraction is reported here as \%terrigenous. Although, technically this fraction may include non-terrigenous components such as biogenic silica, glauconite and volcanic ash, they are only found in trace amounts in this general area (Stow et al., 1986), as Mississippi River input is such a dominant sediment source.

\section{Carbon Isotopes}

Samples for bulk isotopic analyses were treated with $10 \% \mathrm{HCl}$ to remove carbonates, rinsed with DI water, freeze dried, and then ground with mortar and pestle prior to isotope analyses. Stable carbon $\left(\delta^{13} \mathrm{C}, \% \mathrm{C}\right)$ was measured using a Carlo-Erba elemental analyzer coupled to an isotope ratio mass spectrometer at the University of Maryland Center for Environmental Science Chesapeake Biological Laboratory. Samples were prepared for measurement of natural abundance of radiocarbon at the 
National High Magnetic Field laboratory. Acid treated sediment was combusted in quartz tubes at $850^{\circ} \mathrm{C}$ for $4 \mathrm{~h}$ and then the pure $\mathrm{CO}_{2}$ was collected on a vacuum line using a series of cold traps to remove water vapor and non-condensable gases following the methods of Choi and Wang (2004). The purified $\mathrm{CO}_{2}$ was flame sealed in a $6 \mathrm{~mm}$ ampoule and sent to Woods Hole National Ocean Sciences Accelerator Mass Spectrometry where the samples were prepared as graphic targets and analyzed by accelerator mass spectrometry (Vogel et al., 1984). The radiocarbon signatures are reported in $\Delta^{14} \mathrm{C}$ notation as described by Stuiver and Polach (1977). The ${ }^{14} \mathrm{C}$ blanks were generally between 1.2 and $5 \mu \mathrm{g}$ of carbon, producing a negligible effect on samples, which were over $1200 \mu \mathrm{g}$ of carbon. The analysis of 22 replicate sediment samples yielded an average analytical reproducibility of $\pm 6.8 \%$ for $\Delta^{14} \mathrm{C}$ and $0.2 \%$ for $\delta^{13} \mathrm{C}$. Forty coal samples, representing fossil ${ }^{14} \mathrm{C}$ dead carbon, were analyzed to access our procedural blank of combustion, graphitization, and target preparation, over the course of this study. The average $\Delta^{14} \mathrm{C}$ value was $-995 \pm 7 \%$. We also ran 25 azalea leaf standards collected in Tallahassee, Florida in 2013; the average $\Delta^{14} \mathrm{C}$ value was $31 \pm 8 \%$.

\section{Benthic Foraminifera}

Following extrusion (methods provided above), five sub-samples from the surface of the sediment cores $(0-2,2-4,4-6,6-8$, and $8-$ $10 \mathrm{~mm}$ ) and one sub-sample from down-core (20-22 $\mathrm{mm}$ ) were used for benthic foraminifera analysis following methods similar to Schwing et al. (2018). Briefly, sub-samples were weighed and washed with a sodium hexametaphosphate solution through a 63$\mu \mathrm{m}$ sieve to disaggregate detrital particles from foraminiferal tests (Osterman, 2003). The fraction remaining on the sieve (>63$\mu \mathrm{m})$ was dried in an oven at $32^{\circ} \mathrm{C}$ for $12 \mathrm{~h}$, weighed again, and stored at room temperature (Osterman, 2003). Between 200 and 400 individuals from each subsample were identified to the species-level and counted. The fraction of the sample that was identified was then weighed. It was necessary to count between 200 and 400 individuals per sample to distinguish $2 \%$ significant variability in density and relative abundance between sample intervals (Patterson and Fishbein, 1989). Multiple taxonomic references were used (d'Orbigny, 1826, 1839; Williamson, 1858; Jones and Parker, 1860; Parker and Jones, 1865; Brady, 1878, 1879, 1884; Cushman, 1922, 1923, 1927; Stewart and Stewart, 1930; Phleger and Parker, 1951; Parker et al., 1953; Parker, 1954). The number of specimens with visibly fractured tests was counted and reported as the fracture percentage versus the total number of specimens identified as a taphonomical indicator of turbulent flow redistribution (Ash-Mor et al., 2017).

\section{Hydrocarbon Analyses}

Samples were kept frozen until freeze-dried at the Marine Environmental Chemistry Laboratory (MECL, College of Marine Science, University of South Florida). Approximately $1.0 \mathrm{~g}$ of freeze-dried and homogenized sediment was extracted using an Accelerated Solvent Extraction system $\left(\mathrm{ASE}^{\circledR}\right.$ 200, Dionex) under high temperature $\left(100^{\circ} \mathrm{C}\right)$ and pressure $(1500 \mathrm{psi})$ with hexane:dichloromethane (9:1 v:v). Deuterated standards were added to samples prior to extraction to monitor matrix effects and correct for losses during extraction (d10-acenaphthene, d10-phenanthrene, d10-fluoranthene, d12-benz(a)anthracene, d12-benzo(a)pyrene, d14-dibenz(ah)anthracene, $\mathrm{d}_{50}$-tetracosane, $\mathrm{d}_{15}$-pentadecane, $\mathrm{d}_{32}$-dotriacontane, $\mathrm{d}_{4}$-cholastane). For extraction in the ASE, we applied a one-step extraction and clean up procedure using a predetermined packing of the extraction cells (Kim et al., 2003; Choi et al., 2014; Romero et al., 2018) using a $11 \mathrm{ml}$ extraction cell with glass fiber filter (pre-combusted at $450^{\circ} \mathrm{C}$ for $4 \mathrm{~h}$ ), $5 \mathrm{~g}$ silica gel (high purity grade, 100200 mesh, pore size 30A, Sigma Aldrich, United States; pre-combusted at $450^{\circ} \mathrm{C}$ for $4 \mathrm{~h}$, and deactivated $2 \%$ ), and sand (pre-combusted at $450^{\circ} \mathrm{C}$ for $4 \mathrm{~h}$ ). Sediment extracts were concentrated to $\sim 2 \mathrm{ml}$ in a RapidVap (LABONCO RapidVap ${ }^{\circledR}$ Vertex $^{\text {TM }} 73200$ series) and further concentrated to about 100-300 $\mu$ l by gently blowing with a nitrogen stream. An internal standard was added (d14-terphenyl; Ultra Scientific ATS-160-1) to all samples prior to GC/MS analysis. All solvents used were at the highest purity available. Two extraction control blanks were included with each set of samples (18 samples).

We followed modified EPA methods and QA/QC protocols (8270D, 8015C). Targeted compounds included aliphatics (C12C37 n-alkanes, isoprenoids), PAHs (2-6 ring polycyclic aromatic hydrocarbons including alkylated homologs), and biomarkers [C27-C35 hopanoids, C27-C29 steranes, C20-C28 triaromatic steroids (TAS)]. Hydrocarbon compounds were quantified using GC/MS/MS (Agilent 7680B gas chromatograph coupled with an Agilent 7010 triple quadrupole mass spectrometer) in multiple reaction monitoring mode (MRM) to target multiple chemical fractions in one-run-step. Molecular ion masses for hydrocarbon compounds were selected from previous studies (Romero et al., 2015, 2018; Sørensen et al., 2016; Adhikari et al., 2017) (Supplementary Tables 2a,b). All samples were analyzed in splitless injections, inlet temperature of $295^{\circ} \mathrm{C}$, constant flow rate of $1 \mathrm{ml} / \mathrm{min}$, and a MS detector temperature of $250^{\circ} \mathrm{C}$ using a RXi-5sil chromatographic column. The GC oven temperature program was $60^{\circ} \mathrm{C}$ for $2 \mathrm{~min}, 60^{\circ} \mathrm{C}$ to $200^{\circ} \mathrm{C}$ at a rate of $8^{\circ} \mathrm{C} / \mathrm{min}, 200^{\circ} \mathrm{C}$ to $300^{\circ} \mathrm{C}$ at a rate of $4^{\circ} \mathrm{C} / \mathrm{min}$ and held for $4 \mathrm{~min}$, and $300^{\circ} \mathrm{C}$ to $325^{\circ} \mathrm{C}$ at a rate of $10^{\circ} \mathrm{C} / \mathrm{min}$ and held for $5 \mathrm{~min}$. Source electron energy was operated at $70 \mathrm{eV}$, and argon was used as the collision gas at 1 mTorr pressure.

For accuracy and precision of analyses we included laboratory blanks for every 12-14 samples, spiked controls for every 1418 samples, tuned MS/MS to PFTBA (perfluorotributylamine) daily, checked samples with a standard reference material (NIST 2779) daily, and reanalyzed sample batches when replicated standards exceeded $\pm 20 \%$ of relative standard deviation (RSD), and/or when recoveries were low. Recovery ranged within QA/QC criteria of 50-120\%. PAH concentrations are reported as recovery corrected. Each analyte was identified using certified standards (Chiron S-4083-K-T, Chiron S-4406-200T, NIST 2779) and performance was checked using a 5point calibration curve $(0.04,0.08,0.31,1.0 \mathrm{ppm})$. Quantitative determination of compounds was conducted using response factors (RFs) calculated from the certified standard NIST2779. 
Hydrocarbon compounds are expressed as sediment dry weight concentrations.

\section{Hydrocarbon Source Identification}

We used a tiered analytical approach for the identification of hydrocarbon sources in the sediment samples collected. First, we determined the concentration of hydrocarbon groups in the sediment samples (aliphatics, PAHs, and biomarkers (hopanoids, steranes, and TAS) to establish temporal (as profiles) and spatial (surface maps) changes of hydrocarbon concentrations and composition. Second, we determined and compared diagnostic oil ratios between potential sources and the samples (for details see below). Third, we compared the distribution pattern of $n$-alkanes and PAHs among samples.

Diagnostic oil ratios were calculated for all crude oil standards (NIST Macondo oil: MC252; Southern Louisiana Sweet crude oil: LC; southern GoM Akal Bravo oil: $A B$ ) and samples to discriminate hydrocarbon sources. Careful should be taken when applying diagnostic ratios to deep-sea sediments because of multiple weathering processes affecting the composition of hydrocarbons during sinking through the water column and after reaching the seafloor. For example, low molecular weight PAHs (LMW, containing 2-3 ring PAHs) are abundant in petrogenic sources while high molecular weight PAHs (HMW, containing 46 ring PAHs) are abundant in pyrogenic sources. However, HMW PAH can become more abundant due to the loss of LMW PAHs during weathering processes (e.g., dissolution, biodegradation). Alkane ratios were used to identify natural vs. oil sources

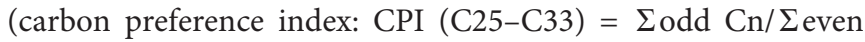
$\mathrm{Cn}$ ) if samples were weathered (low molecular weight alkanes: $\% n$-alkanes $\left.=\Sigma \mathrm{C} 14-\mathrm{C} 24 / \mathrm{sum}(\mathrm{C} 12-\mathrm{C} 37)^{*} 100\right)$. Samples with $\mathrm{CPI}<2.0$ and $\% n$-alkanes $<25 \%$ indicate a weathered petrogenic source (Xing et al., 2011; Romero et al., 2015, 2021; Herrera-Herrera et al., 2020).

Other compounds, more resistant to weathering, can be used to identify specific oil sources (hopanes, steranes, triaromatic steroids). However, diagnostic oil biomarker ratios (using hopane, sterane, and triaromatic steroid compounds) known to fingerprint DwH oil or other crude oils have mostly been tested in samples collected from coastal environments (Wang and Fingas, 2003, Wang et al., 2006; Mulabagal et al., 2013; Aeppli et al., 2014) and a few in deep-sea sediments (Romero et al., 2015, 2017; Stout et al., 2016). In addition, some of these biomarker compound groups (e.g., steranes) have been shown to degrade in the marine environment years after an oil spill (Wang et al., 2001; Prince et al., 2002; Gros et al., 2014). Therefore, we tested if biomarker ratios used in previous studies (Wang and Fingas, 2003, Wang et al., 2006; Mulabagal et al., 2013; Aeppli et al., 2014; Romero et al., 2015, 2017) can be used to fingerprint deep-sea sediments, where organic matter and oil residues are naturally exposed to long-term weathering processes. Specifically, we compared the MC252 oil standard (NIST 2779) with samples collected at the DwH site (DwH-01), an area known to contain weathered oil residues from the DwH spill (Chanton et al., 2015; Romero et al., 2015; Stout et al., 2016). Also, samples from the DwH-01 site, the closest site to the $\mathrm{DwH}$ wellhead, sampled from 2011 to
2013, showed the presence and preservation of oil residues in the sediments from the DwH spill (Romero et al., 2017).

Only diagnostic ratios with a difference within $\pm 20 \%$ between samples from site DWH-01 and the average of MC252 oil standard $(N=60)$ were used. In previous fingerprinting studies, this criteria for the difference between samples and an oil standard has been established based on the relative standard deviation value (RSD: 14-20\%) of a standard analyzed over a period of time (analytical uncertainty) (Aeppli et al., 2014; Meyer et al., 2017). Our analysis of biomarkers using GC/MS/MSMRM had an RSD of $4.8 \%$ over a time period of 6 months using the MC252 oil standard. The application of GC/MS/MSMRM increases selectivity, improved baseline and signal-tonoise ratio, and successfully separates target compounds from interferences compared to the conventional GC/MS-SIM method (Adhikari et al., 2017). Altogether, the GC/MS/MS-MRM method improves the analytical uncertainty in the analysis of biomarker compounds. However, environmental sample replicates collected in deep-sea areas of the GoM have shown that RSD varies between $4 \%$ to $22 \%$ for biomarker compounds, indicating natural variability in the area (Romero et al., 2015). Therefore, diagnostic biomarker ratios of $\mathrm{DwH}$ oil residues at depth were selected using the RSD value of $20 \%$, to account for the natural variability in deep sea environments. Ratios with a difference within $\pm 20 \%$ between samples from site DWH-01 and the average of MC252 oil standard seem resistant to weathering and other natural processes at depth in the GoM, and are suitable for fingerprinting. The matching ratios were then calculated for all sites studied and analyzed using a Principal Component Analysis (PCA; JMP ${ }^{\circledR}$ Pro 14.0). Also, cross plots of alkane diagnostic ratios were done to identify oil vs. natural sources in the region. In addition, the relative abundance (\%) of hydrocarbon groups was plotted for each site studied to identify areas with high content of LMW PAHs (2-3 rings) due to inputs from natural seeps.

Only samples indicating oil content (using alkane ratios), no natural seep inputs (with low \%LMW PAHs), a distinct distribution pattern of $n$-alkanes and PAHs indicating weathered oil residues, and a match with the MC252 oil standard (using biomarker ratios) were identified to contain $\mathrm{DwH}$ oil residues as the most probable oil source.

\section{RESULTS}

All sites yielded sediment cores with active deposition over the past $\sim 100$ years. Core analyses revealed a range of sediment textures, composition and accumulation rates indicating that sedimentation processes varied throughout the study area. Downcore data were utilized for some analyses to provide a longer time-scale context (Figure 2) and to assess the historical prevalence of down-slope sediment transport as indicated by various sedimentary structures present throughout the study area. All other analyses focused on the surficial sediments (0$20 \mathrm{~mm}$ ) to identify recent patterns that may be associated with deposition and redistribution of $\mathrm{DwH}$ contaminated sediments. We have provided maps in figures and supplementary figures as a mechanism to visualize the data and to communicate 


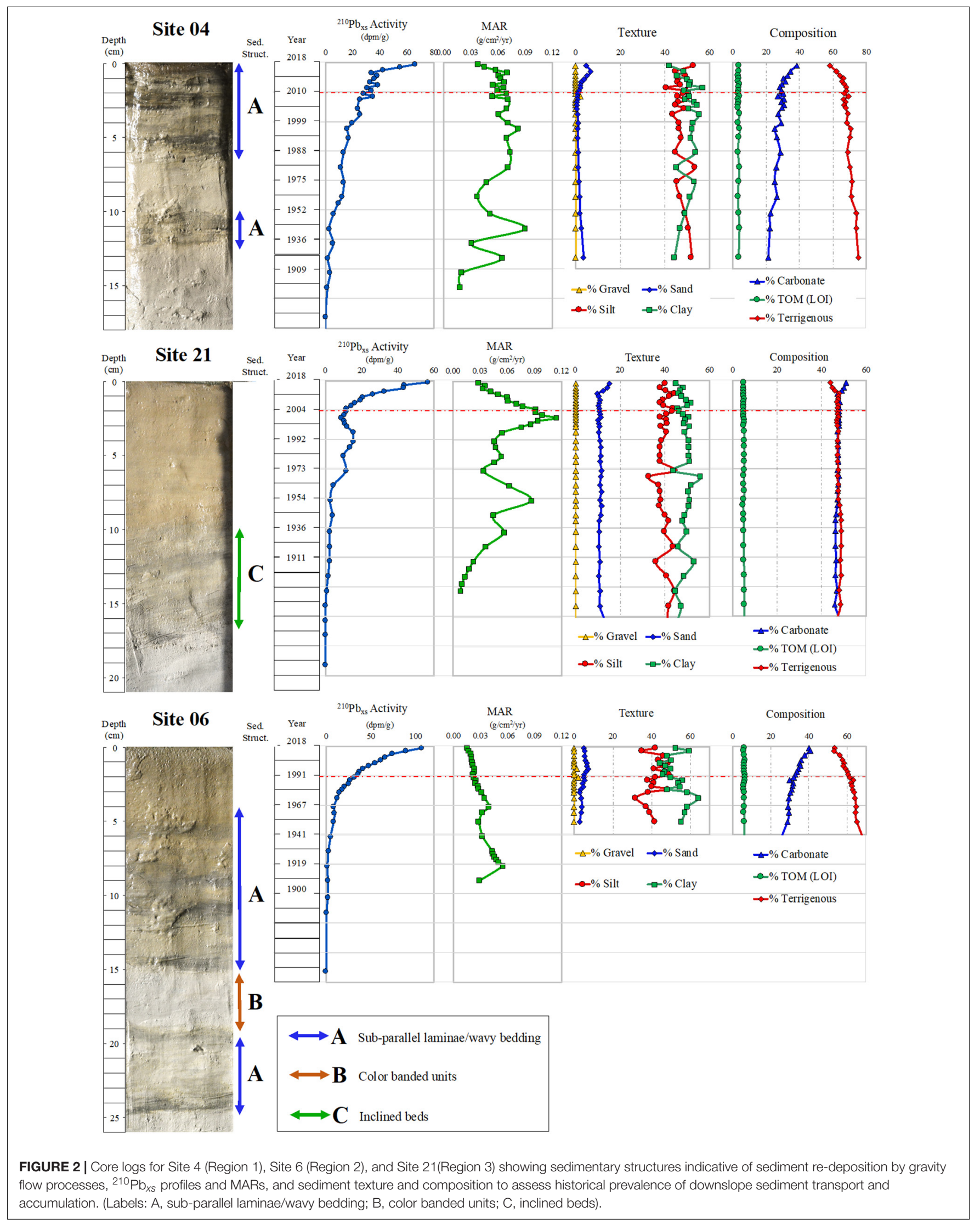




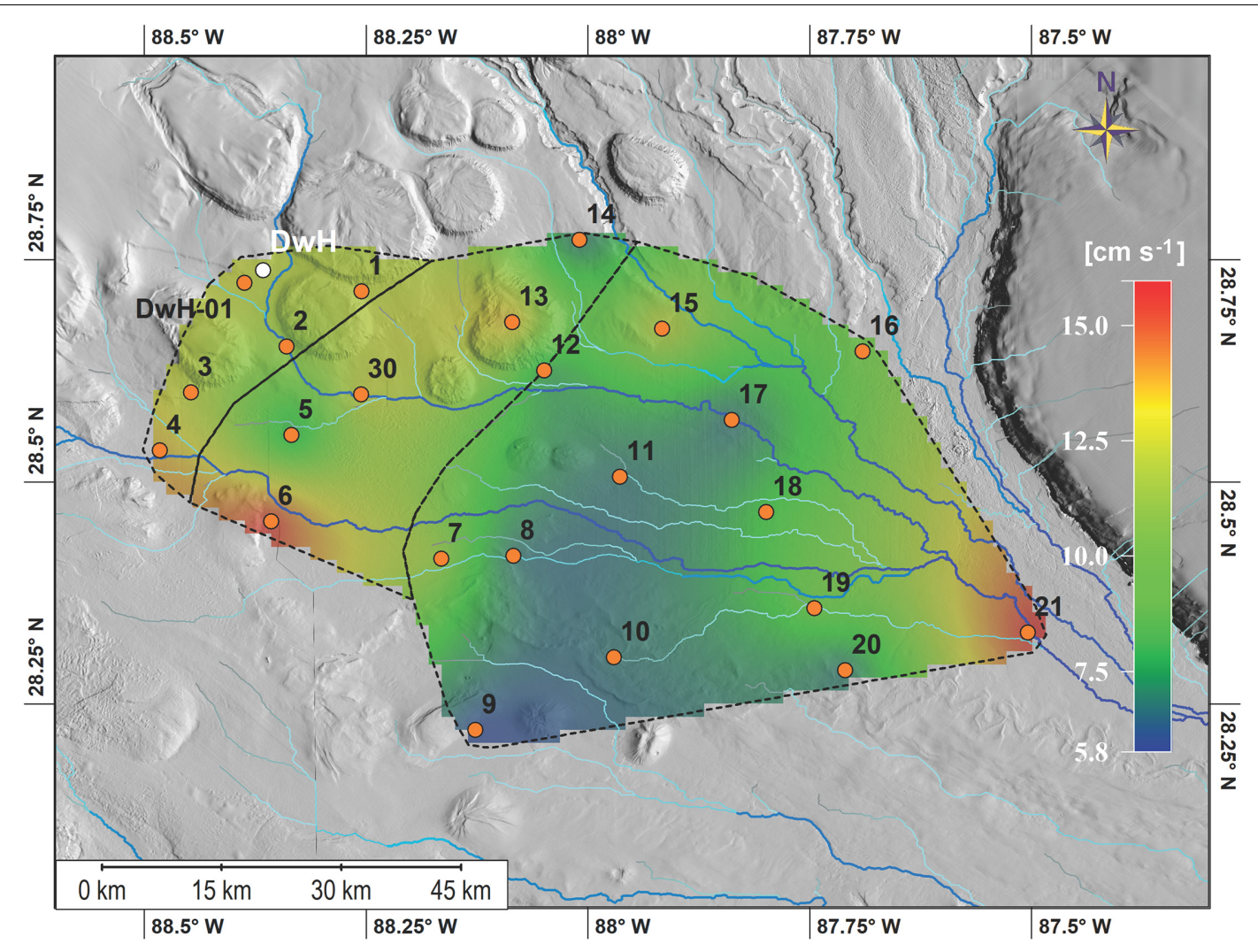

FIGURE 3 | Heat map of flow speed of first peak in particle resuspension. Regions discussed are outlined by the dashed black lines. Region 1 is in the NW and Region 3 in the SE. Blue lines indicate channels as modeled by watershed analysis.

the observed variations in the data. Interpolations of data in the areas between the individual coring locations were dependent on parameters set in the contouring program (Golden Software Surfer 9.0) and were thus not discussed in this manuscript.

\section{Flume}

Flume experiments showed that sediment particle erosion behavior was not uniform across the various sedimentary environments on the seafloor (Table 1). The uppermost layer of sediment (top $2 \mathrm{~mm}$ ) from each core eroded at different flow speeds, producing maximum peaks in total number of particle counts at flow speeds from $5.72 \mathrm{~cm} \mathrm{~s}^{-1}$ to $16 \mathrm{~cm} \mathrm{~s}^{-1}$ (Table 1 and Figure 3). Several sediment cores exhibited a second peak at higher flow speeds (sites 10,11,14,17, and 20). In all cores ( sites $8,9,10,17,19$, and 20) that had a first peak in particle resuspension at low flow speeds, a decrease in resuspended particle concentration was observed following the initial peak resuspension of particles. A second larger peak, produced by a complete collapse of the surface sediment layer, occurred in all cores at flow speeds exceeding $13.7 \mathrm{~cm} \mathrm{~s}^{-1}$. Sediments from cores that did not have the initial peak in resuspended particles (sites $4,5,6,12,13,15,16,21,30$, and DwH-01) had low numbers of particles resuspended until a rapid disintegration of the surface sediment layer occurred $>13.7 \mathrm{~cm} \mathrm{~s}^{-1}$.
Distinct peaks in total volume with increased flow speed were recorded for each core analyzed. Average area of individually eroded particles varied only slightly between 0.39 and $0.63 \mathrm{~mm}^{2}$ in all cores, however, total eroded volume of particles varied from 4.4 to $535 \mathrm{~cm}^{3}$ (Table $\mathbf{1}$ ).

\section{Short-Lived Radioisotopes}

Short-lived radioisotope analyses yielded ${ }^{210} \mathrm{~Pb}_{x s}$ activity profiles utilized to provide age control and sedimentation rates at multicore sites over the past $\sim 120$ years. ${ }^{210} \mathrm{~Pb}_{x s}$ profile shape and MAR, averaged over various time periods, were used to characterize the spatial patterns of sediment distribution and accumulation.

${ }^{210} \mathrm{~Pb}_{x s}$ activity profile shapes varied with some sites exhibiting exponential profiles and others non-exponential profiles (Figure 2 and Supplementary Figures $3 \mathbf{a}-\mathbf{c}$ ). Nonexponential profiles ranged from small mm-scale plateaus in activity to profiles with large $\mathrm{cm}$-scale plateaus. Some profiles contained few plateaus, and some contained multiple plateaus. These profiles were utilized to assess the relative magnitude and frequency of episodic or pulsed accumulation (plateaus in activity in profiles) vs. areas with stable consistent accumulation (exponential profiles).

The spatial pattern of the pulse index reveals variability in the prevalence of sediment accumulation from episodic events 


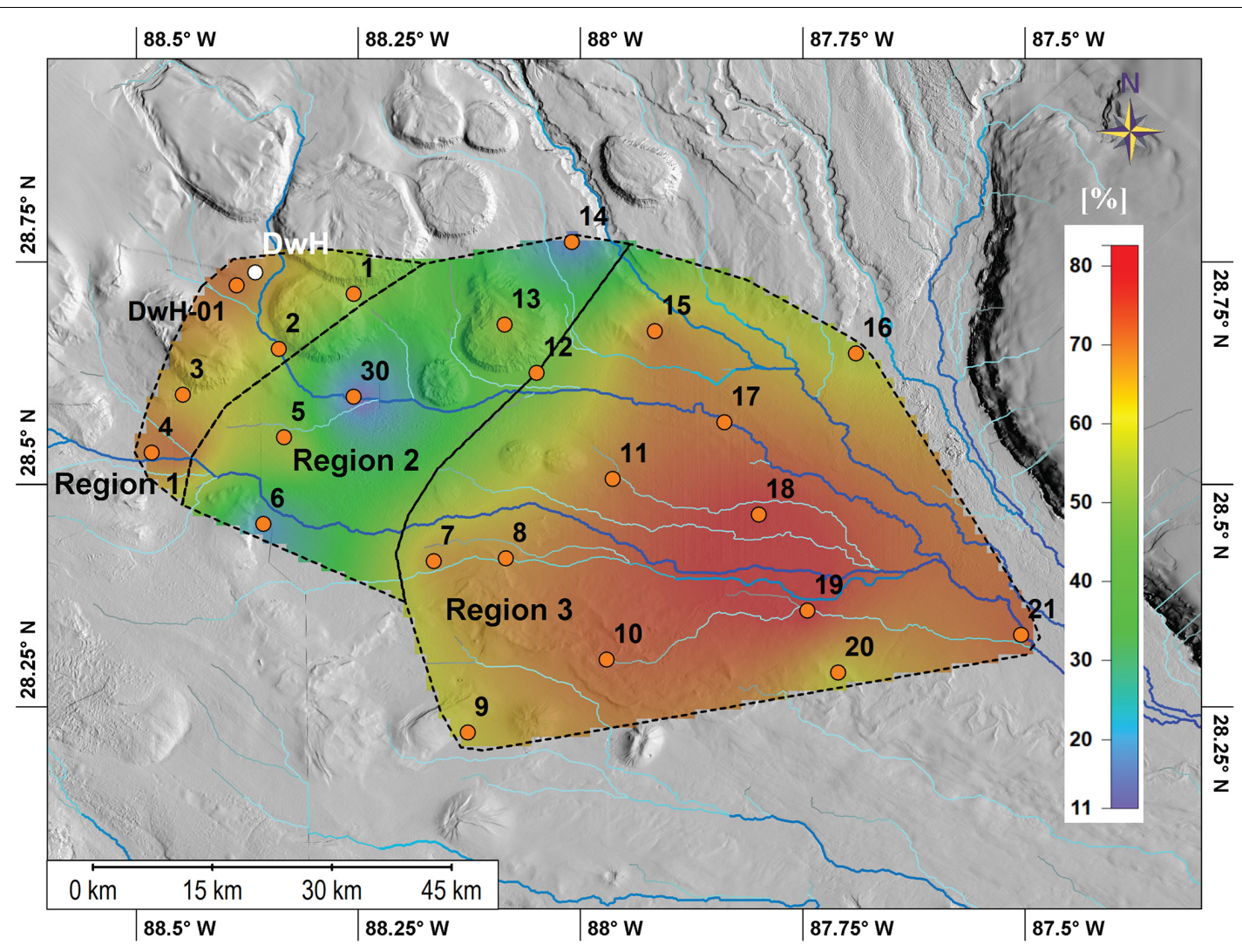

FIGURE 4 | Heat map of weighted pulsed input in study area. The three regions identified in this study are marked by black lines and are labeled Region 1, 2, and 3 form the NW to the SE. Scale describes the percentage of pulsed inputs in the study area.

over the past $\sim 120$ years (Figure 4 ). In the northwestern portion of the study area (sites 1, 2, 3, 4, and DwH-01) a high index, reflecting frequent episodic sedimentation events, was observed. The central portion of the study area consists of low index values (sites 5, 6, 12,13,14, and 30) reflecting a more stable, consistent sediment accumulation history. The southeastern portion of the study area shows high index values (sites $7,8,9,10,11$, $15,16,17,18,19,20$, and 21) but with the highest episodic sedimentation events observed in the study area, in terms of magnitude and frequency.

Sediment MAR's were determined using ${ }^{210} \mathrm{~Pb}_{x s}$ age dating. Differing time periods were evaluated to characterize accumulation rates from a long (1950-2018) to short periods for characterizing events pre-spill (2006-2009; Figure 5A), during and after the spill related to the MOSSFA event (20102013; Figure 5B), and post-spill associated to redistribution of sediments (2014-2018; Figure 5C). Spatial patterns of MAR's from 1950 to 2018 are consistent with the areas of episodic sedimentation identified by the ${ }^{210} \mathrm{~Pb}_{x s}$ pulse index, further corroborating the spatial variability in the influence of episodic sedimentation events (Figure 4). For the three recent time periods compared in this study, there are potential shifts in "hot spots" of higher accumulation with site 18 consistently being a "hot spot" for accumulation in all three periods. Site 9 shows increased MAR's in the 2010-2013 time period. In the 2014-2018 period, there are higher MAR's at site 16 near the base of the DeSoto Canyon as compared to the 2006-2009 and 2010-2013 time periods (Figures $5 \mathrm{~A}-\mathrm{C}$ ).

\section{Sedimentology}

All cores exhibited intact detailed stratigraphy, contained numerous, well-preserved primary sedimentary structures, and very few secondary sedimentary structures (e.g., bioturbation). The most common structures were thin, $\mathrm{mm}$-scale, sub-parallel laminae and wavy bedded units with no clearly defined lower boundaries (Figure 2). These structures were found throughout the entire study area in all depocenter types (Table 1). Inclined and color banded beds (Figure 2) were less common, and sparsely dispersed throughout all but the northeastern-most portion of the study area (Table 1). Generally, sedimentary structures were better defined in the upper few 10's of cm of cores (Table 1).

Sediment grain size and composition was averaged over the surficial $0-4 \mathrm{~mm}$ and $10 \mathrm{~mm}$ intervals and varies throughout the study area. Grain size is reported as \%gravel, \%sand, $\%$ silt, \%clay, and \%mud (\%silt $+\%$ clay), and composition is reported as \%carbonate, \%TOM (total organic matter by LOI), and \%terrigenous (Table 2 and Supplementary Figures 4-8). \%Carbonate ranged from $45 \%$ to $60 \%$ with lowest concentrations in the NW portion of the study area and increasing to the SE. \% TOM ranged from $4.4 \%$ to $7.1 \%$ with highest values in the 

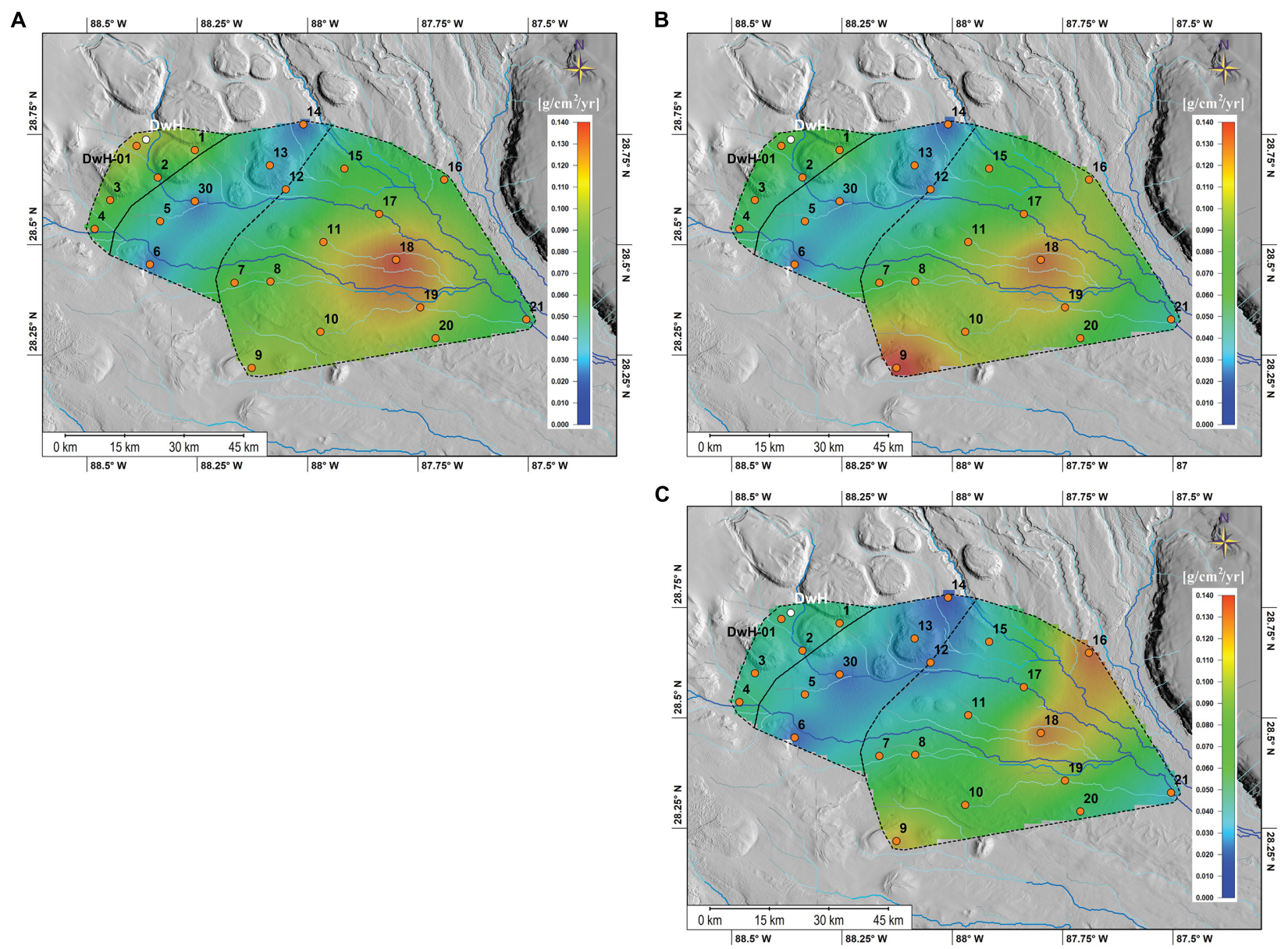

FIGURE 5 | Heat maps of average sediment accumulation rates determined from ${ }^{210} \mathrm{~Pb}_{x s}$. (A) Pre-Spill (2006-2009), (B) 2010-2013, and (C) 2014-2018. Regions discussed are outlined by the dashed black lines. Region 1 is in the NW and Region 3 in the SE. Blue lines indicate channels as modeled by watershed analysis.

NW and decreasing to the SE. Sediment grain size showed more spatial variability than composition. \%Gravel was zero in all sites except site 03, which contained large pteropod fragments. $\%$ Sand ranged from $0.3 \%$ to $12.9 \%$ with highest values in the $\mathrm{SE}$, lowest values in the $\mathrm{N}$, and moderate values in the $\mathrm{W}$ portion of the study area. \%Silt ranged from $35.3 \%$ to $58.5 \%$ with highest values in the NW, lowest values in the NE and SE, and modest in the SW portion of the study area. \%Clay ranged from $39.9 \%$ to $63.3 \%$ with highest values in the NE, modest through the central to S, and lowest in the NW and SE areas. Highest \%carbonate values were consistently associated with the highest $\%$ sand, which consisted of sand size biogenic carbonate particles (Supplementary Figures 4-8).

\section{Carbon Isotopes}

The sedimentary organic carbon content in percent carbon by weight, $\% \mathrm{C}$, the stable carbon isotopic composition, $\delta^{13} \mathrm{C} \%$, and the radiocarbon content, $\Delta{ }^{14} \mathrm{C} \%$, of the surface $0-2 \mathrm{~mm}$ layer and the $0-10 \mathrm{~mm}$ layer are reported in Supplementary Table 3. Values for the $0-10 \mathrm{~mm}$ depth interval were calculated as the average of the five $2 \mathrm{~mm}$ slices subsampled within that interval. The \%organic carbon of the uppermost interval (0$2 \mathrm{~mm}$ ) varied from 1.3 to $2.9 \%$ and generally decreased from the northwest to the southeast as the water deepened (Figure 6). The $\delta^{13} \mathrm{C}$ of surface $(0-2 \mathrm{~mm})$ organic matter varied from -20.7 to $-22.5 \%$ and was more depleted to the northwest and exhibited a minimum in the center of the study area (Figure 7). There was a significant correlation of increasing $\delta^{13} \mathrm{C}$ with decreasing \%organic carbon ( $p=0.01, r=0.512, n=24)$. Radiocarbon content in the surficial layer $(0-2 \mathrm{~mm})$ varied from -167 to $-319 \%$ across the study area (Figure 8). The most depleted values were observed at about 2,300 $\mathrm{m}$ depth on the north east and western sides of the study area. The central portion of the study area exhibited ${ }^{14} \mathrm{C}$ enriched surface sediments downslope of the $\mathrm{DwH}$ site, in water depths ranging from 1,700 to $2,100 \mathrm{~m}$, grading to more depleted values to the southeast. None of these parameters correlated with depth.

\section{Benthic Foraminifera}

Benthic foraminifera density and fracture percentage are presented in Supplementary Table 4. Benthic foraminifera density ranged from 15 to 74 individuals $/ \mathrm{cm}^{3}$ and generally 
TABLE 2 | Sedimentological data.

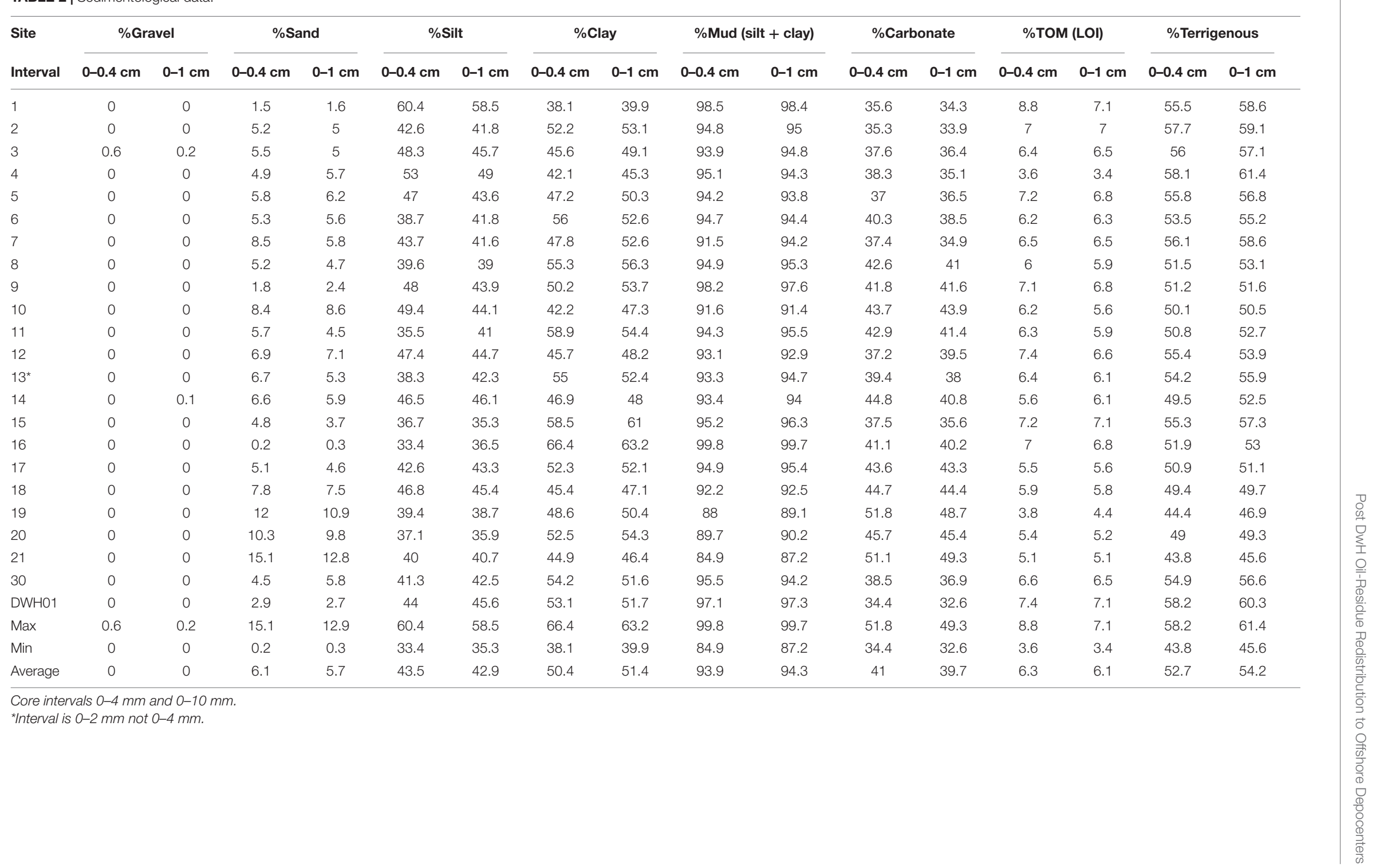




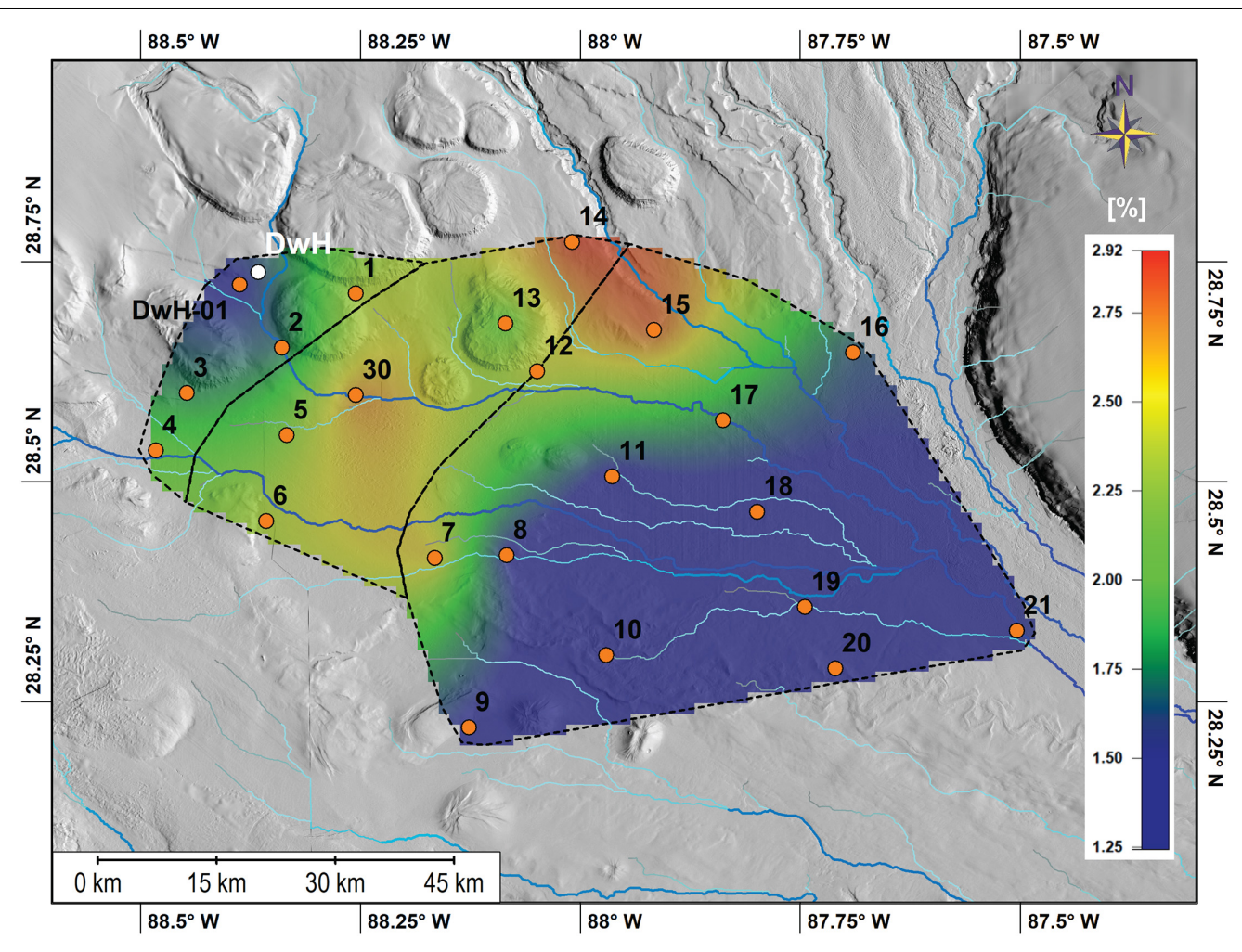

FIGURE 6 | Heat map of \%carbon content of the upper $2 \mathrm{~mm}$ of the cores. Regions discussed are outlined by the dashed black lines. Region 1 is in the NW and Region 3 in the SE. Blue lines indicate channels as modeled by watershed analysis.

increased from the northwestern (e.g., site 1 mean density: 19 individuals $/ \mathrm{cm}^{3}$ ) to the southeastern (e.g., site 24 mean density: 38 individuals $/ \mathrm{cm}^{3}$ ) portion of the study area. Benthic foraminifera fracture percentage ranged from 7.5 to $25.1 \%$ with the highest mean fracture percentage in the north-central portion of the study area (e.g., site 12 mean: 20.6\%, site 14 mean: $16.0 \%)$. Maxima in fracture percentage were typically found at 6$10 \mathrm{~mm}$ depth (sites $1,9,12$, and 16). These maxima were often coincident with variability in other parameters consistent with resuspension (Figure 9).

\section{Hydrocarbon Analyses}

We identified 10 biomarker ratios that can be used as diagnostic biomarker ratios of $\mathrm{DwH}$ oil residues at depth (Figure 10). These biomarker ratios determined for samples from DWH01 site lie within $\pm 20 \%$ of the MC252 standard ratios. The fewer biomarker ratios that matched with the MC252 standard compared to coastal studies may indicate that more compounds are susceptible to multiple weathering processes at depth (e.g., dissolution, degradation, dispersion). Source apportionment of hydrocarbons in the study area after the spill was determined using principal component analysis (PCA) of the biomarker ratios identified in Figure 10. The PCA results in Figure 11 show that $46 \%$ of the sites in $2010-2013$ and $58 \%$ of the sites in 2014-2018 contain oil-residues similar to the MC252 oil standard (all located in the same PCA space) and distinct from other reference oil samples from the GoM. PCA results are supported by cross plots of alkane diagnostic ratios (Figure 12) and \%abundance plots of hydrocarbon compounds groups (Supplementary Figures 9a,b). Caution should be taken when interpreting deep-sea data, because oil-residues deposited at depth, regardless of the source, are highly weathered. For example, Figure 12 shows that several sites in both time periods (2010-2013: sites 1, 14, 8; 2014-2018: sites DwH-01, 1, 2, 12, $14,16)$ contain oil-residues (CPI $<2.0$ indicates oil-residues; $\% \mathrm{C} 14-\mathrm{C} 24<25 \%$ indicates heavily weathered samples) but with a dominant hydrocarbon source different than $\mathrm{DwH}$ oil, as shown by the PCA results (Figure 11). Also, some sites that were designated by the PCA to potentially contain mostly DwH oil-residues (shown in orange color sites 7 and 18 for 2010-2013, and sites 9 and 10 for 2014-2018) are shown in Figure 12 to be mixed with other sources different than oilresidues (e.g., terrestrial), therefore we have classified these sites to contain mixed sources of hydrocarbons (shown in orange color in Figures 11-13 and Supplementary Figures 10a,b). In addition, the results from the PCA analysis and cross plots were supported by distinct distribution patterns of $n$-alkanes and PAHs (Supplementary Figures 11, 12). The samples identified to contain $\mathrm{DwH}$ oil-residues as the potential major source for hydrocarbons in Figures 11, 12, have a distinct $n$-alkane composition with short-chain compounds (C12-C23) less than $2 \%$ abundance, while long-chain compounds (>C30) are more than $10 \%$ abundance (Supplementary Figure 11 and in agreement with Stout et al., 2016). This pattern is 


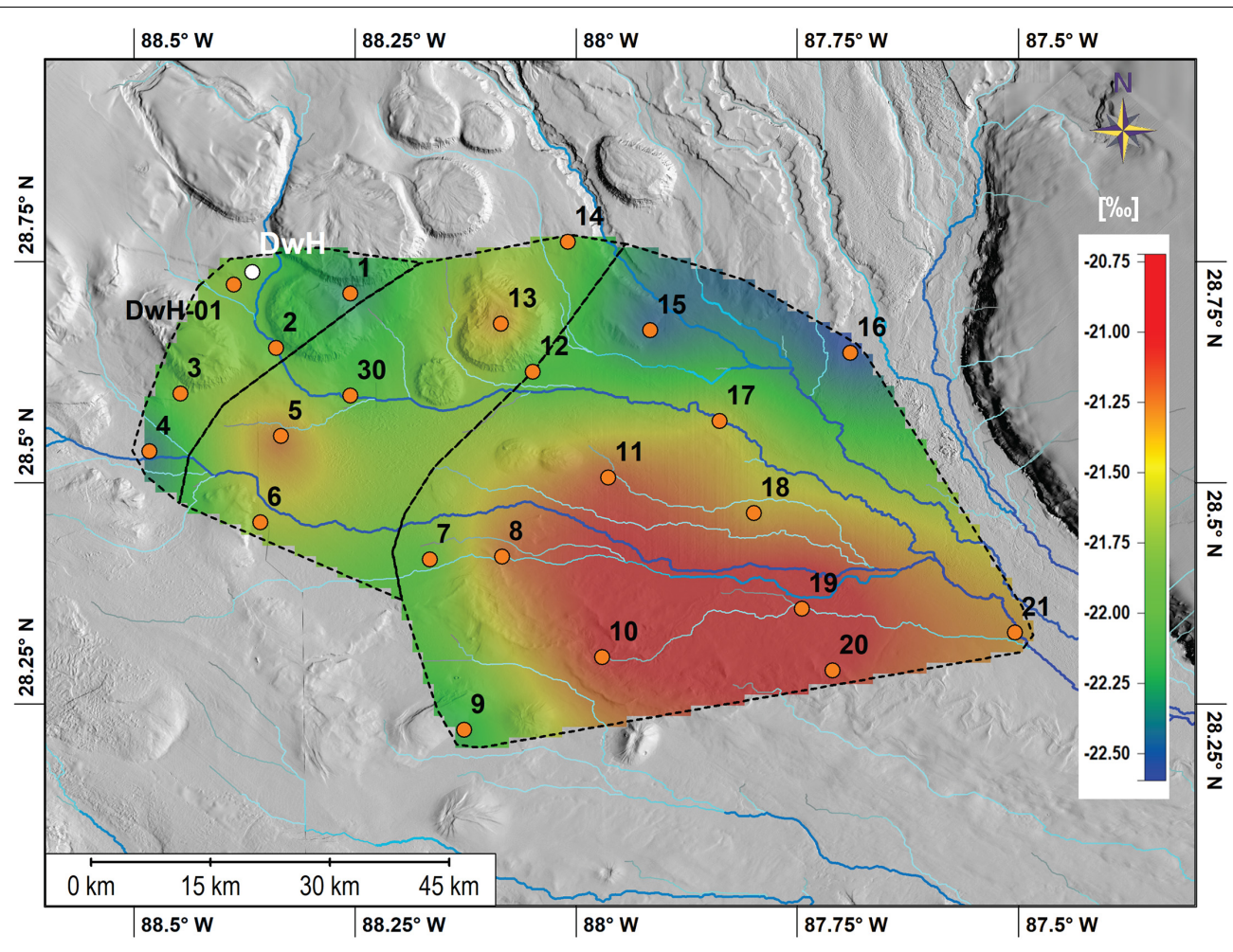

FIGURE 7 | Heat map of $\delta^{13} \mathrm{C}$ surface isotopic composition (0-2 mm). Regions discussed are outlined by the dashed black lines. Region 1 is in the NW and Region 3 in the SE. Blue lines indicate channels as modeled by watershed analysis.

expected from severely weathered oil residues, in which longchain $n$-alkanes are preserved due their lower susceptibility to dissolution and biodegradation. In contrast, other sources (as mixed or unknown in Supplementary Figure 11) show a strong odd-to-even carbon preference for long-chain $n$-alkanes, with C27, C29 and C31 as the most abundant. The observed oddto-even carbon preference for long-chain $n$-alkanes is typical of terrestrial plants. For PAHs, the difference in distribution pattern among sources is as well observed (Supplementary Figure 12). The samples identified to contain $\mathrm{DwH}$ oil-residues as the potential major source for hydrocarbons in Figures 11, 12 have less \%abundance of molecular markers of incomplete combustion such as Re and BeP (Ramdahl, 1983; Wang et al., 1999; Tobiszewski and Namieśnik, 2012), while 4-6 ring PAHs were more abundant due to their higher resistant to weathering processes such as dissolution and biodegradation. This pattern is more notorious by comparing the abundance of $\mathrm{PAH}$ compounds grouped by ring number (Supplementary Figure 13) showing a distribution difference among sources within each year. Also, larger changes between time periods is observed indicating potential additional weathering processing affecting mostly 5-6 ring PAHs (e.g., transformation processes, White et al., 2016). Overall, we found that 15 sites of the 24 studied sites contain DwH oil-residues as the potential major source for hydrocarbons (Figure 13). The results generated using multiple oil diagnostic ratios indicate the significance of using ratios from multiple compound groups (e.g., hopanes, steranes, alkanes, PAHs) for source apportionment of hydrocarbons in deep-sea areas, like in the northern GoM.

Hydrocarbon concentrations, the sum of all compounds analyzed [ $n$-alkanes, isoprenoids, polycyclic aromatic hydrocarbons (PAHs), hopanes, steranes, and triaromatic steroids (TAS)] ranged from $0.2 \mu \mathrm{g} / \mathrm{g}$ to $11.4 \mu \mathrm{g} / \mathrm{g}$, with decreasing concentrations toward southeast of the study area, with some exceptions observed at specific depth layers in the sediments (e.g., site 21) (Figure 13). Specifically, hydrocarbon averages $>2.0 \mu \mathrm{g} / \mathrm{g}$ were observed in the northeast of the study area (sites $\mathrm{DwH}, 1-6,12,13$, and 30), concentrations in the range of $0.9-2.0 \mu \mathrm{g} / \mathrm{g}$ were detected at the center of the study area (sites $7,8,11,14,15,16$, and 17 ), and concentrations $<0.9 \mu \mathrm{g} / \mathrm{g}$ were observed in the southeast area (sites $9,10,19,20,21)$. This general trend in hydrocarbon concentration followed sediment grain size distribution, with higher concentrations where sediments have low carbonate content. In addition, downcore profiles show a large variability in hydrocarbon concentrations in the study area, with enhanced concentrations at specific sediment intervals (Figure 12). Also, specific hydrocarbon compound groups did not show a clear trend with depth (e.g., decrease with sediment depth); therefore, compound relative abundances mostly represent changes in hydrocarbon sources rather than solely biodegradation of hydrocarbons after buried (Supplementary Figures 9a,b). Most abundant compound groups were $n$-alkanes and high molecular weight PAHs (HMW, 4-6 rings). Profiles of HMW PAHs and LMW PAHs (low molecular weight, 2-3 rings) 


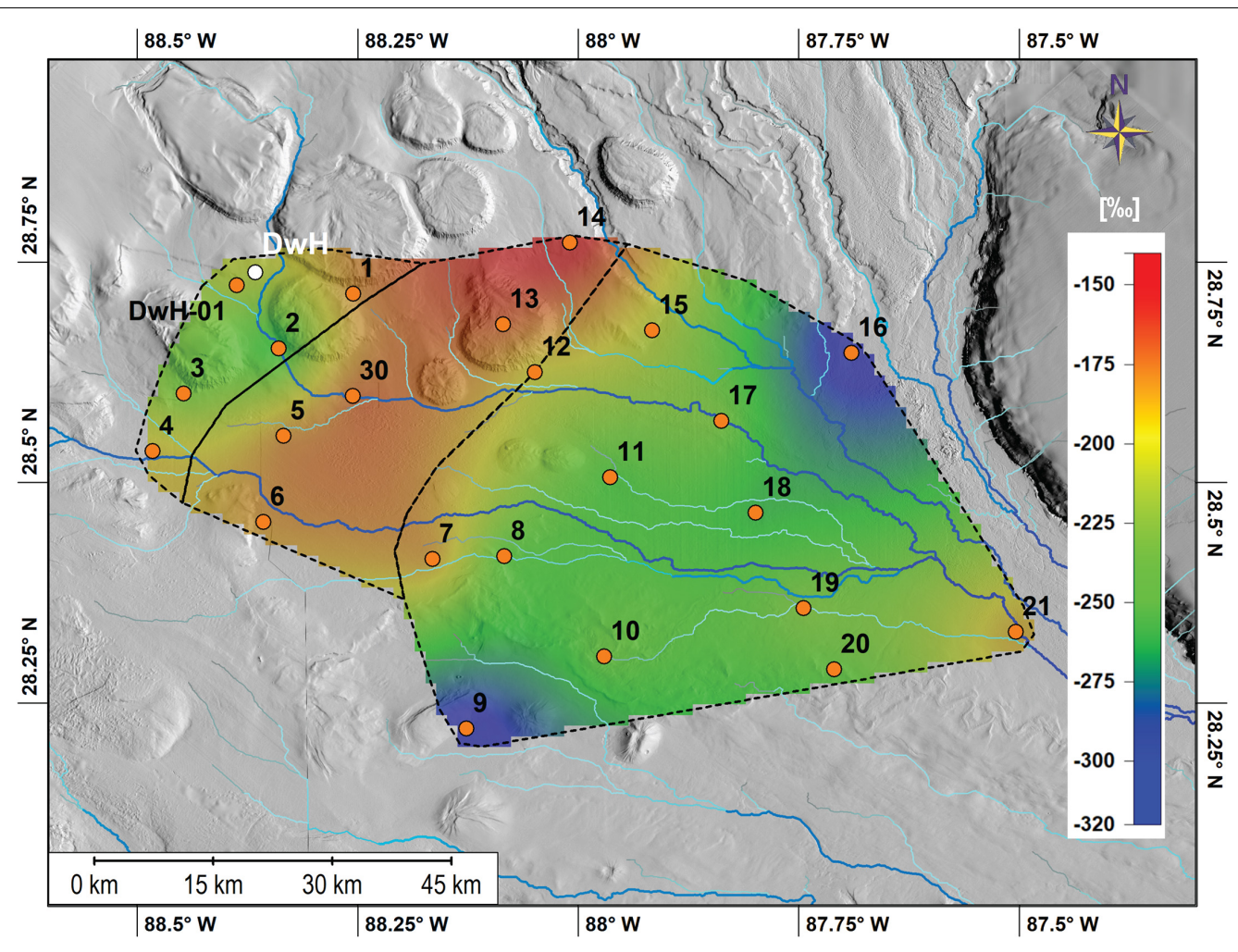

FIGURE 8 | Heat map of $\Delta^{14} \mathrm{C}$ surface activity of the upper $2 \mathrm{~mm}$ of the cores. Regions discussed are outlined by the dashed black lines. Region 1 is in the NW and Region 3 in the SE. Blue lines indicate channels as modeled by watershed analysis.

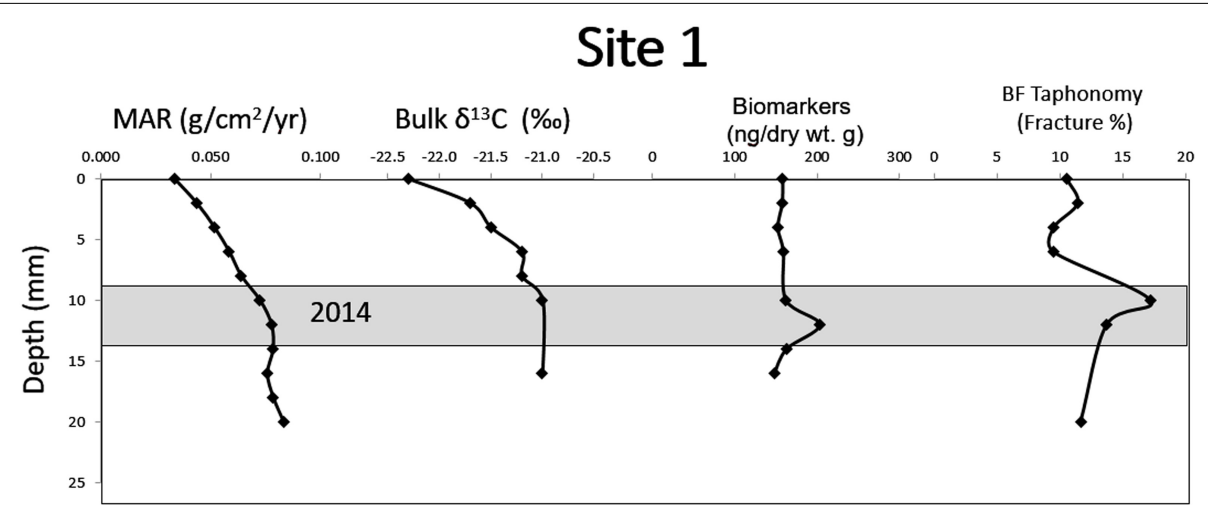

FIGURE 9 | An example of the multi-proxy assessment from station MC01, where an event was identified between 10 and 12 mm depth (year 2014 ) by relatively high mass accumulation rates, homogenous bulk organic stable carbon isotopes, an maxima in organic biomarkers and benthic foraminifera fracture percentage.

showed large variability in some sites in all sediment depth layers (i.e., site 10) or at specific sediment layers (i.e., sites $1,11,17$, and 19), but in all cases HMW PAHs were more abundant.

\section{DISCUSSION}

\section{Spatial Distribution}

All sites were depositional over the past $\sim 100$ years and to various degrees contained sedimentary structures, but there were distinctive variations in accumulation patterns and sediment characteristics throughout the study area. These variations define three distinctive geographic regions with implications for the degree of influence of down-slope sediment transport on sediment accumulation patterns (Figure 4). Bathymetric characteristics, geographic location, and water depth also play a role in the characteristics of each region. Defining characteristics of the regions include episodic vs. stable sediment accumulation patterns as well as surficial sediment characteristics (upper 0$10 \mathrm{~mm}$ of cores). Using ${ }^{210} \mathrm{~Pb}_{x s}$ age dating, cores were assessed 


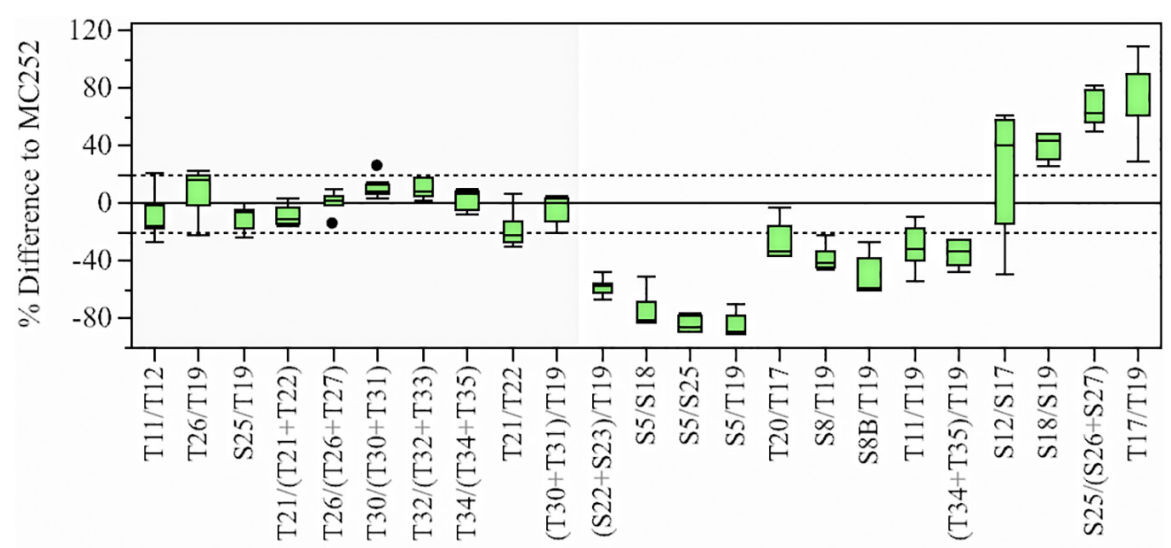

Biomarker ratios

FIGURE 10| Relative difference of biomarker ratios from DW site to the crude oil standard MC252. Graph shows green boxes as the interquartile ranges, with horizontal lines indicating median values and whiskers representing the 10th and 90th percentiles. Black circles denote outlier values, and dotted horizontal lines indicate ratios within $\pm 20 \%$ of the MC252 standard. Information of compounds can be found in Supplementary Tables $\mathbf{2 a , b}$.

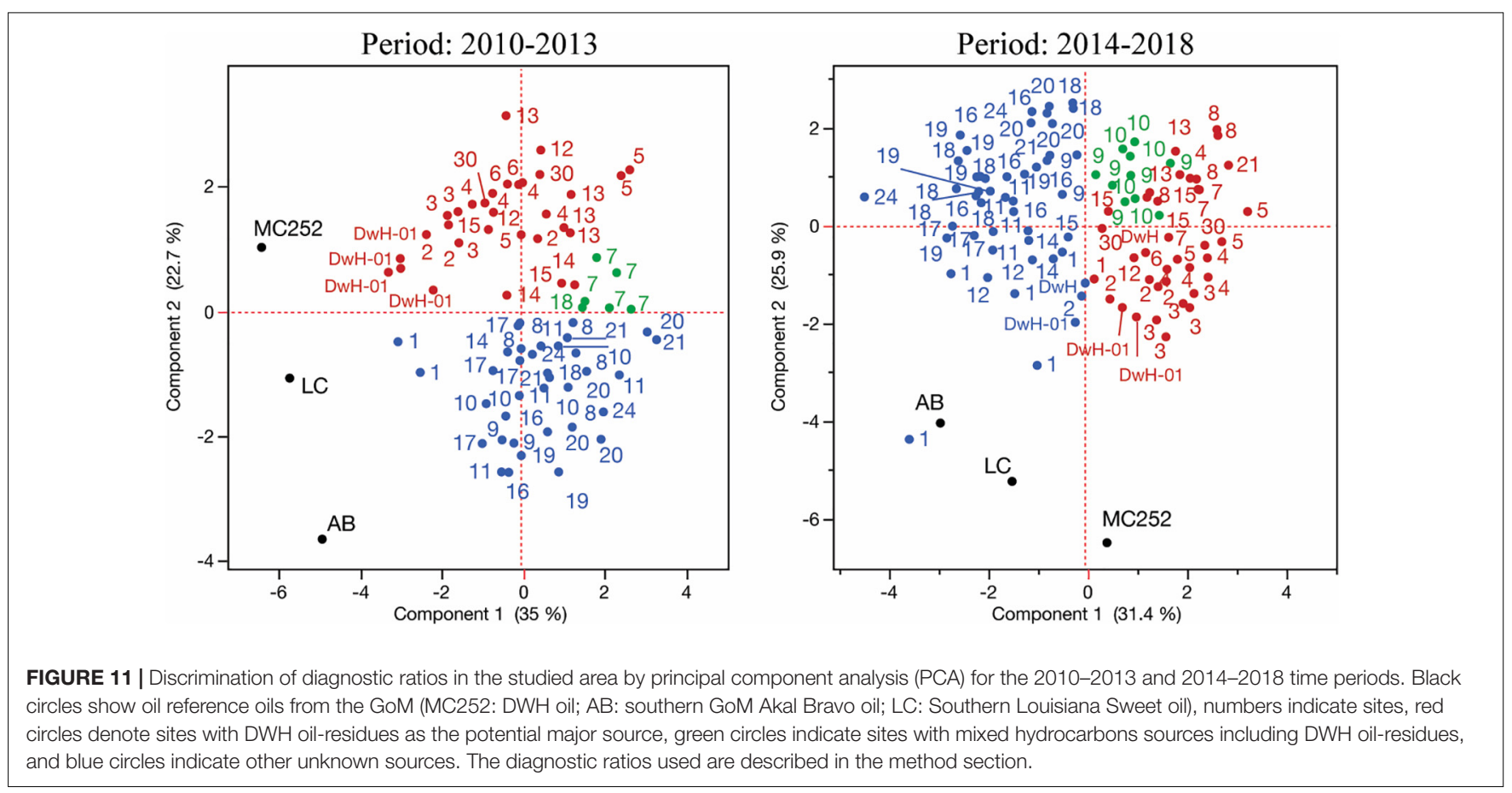

for accumulation patterns from 1950 to 2018 for longer term reference and in greater detail for three time periods, 2006-2009 (pre-spill), 2010-2013 (DwH spill/post-spill), and 2014-2018 (post-spill) to investigate the $\mathrm{DwH}$ spill and potential down-slope redistribution in subsequent years.

(a) Region 1 is in the NW portion of the study area directly surrounding the DwH spill site and includes our station DwH-01, and sites 1, 2, 3, and 4 (Figure 4).

(b) Region 2, includes sites, 5, 6, 12, 13, 14, 30, to the SE of Region 1, consisting of a "belt" running from the NE to SW (Figure 4). (c) Region 3, SE of Region 2, includes sites 7, 8, 9, 10, 11, 15, 16, 17, 18, 19, 20, 21 (Figure 4).

Region 1, in the NW portion of the study area, received the highest inputs of contaminated sediments during and shortly after the spill as previously documented (Chanton et al., 2012, 2015; Passow et al., 2012; Joye et al., 2013; Brooks et al., 2015; Yan et al., 2016; Ziervogel et al., 2016; Romero et al., 2017) (Figure 4). Varying seafloor morphology with steep slopes and valleys was prevalent in this area (Figure 1), providing grounds for seafloor instability and higher potential for down-slope sediment transport. ${ }^{210} \mathrm{~Pb}_{x s}$ data and sedimentary structures indicate pulsed downslope transport accompanied 


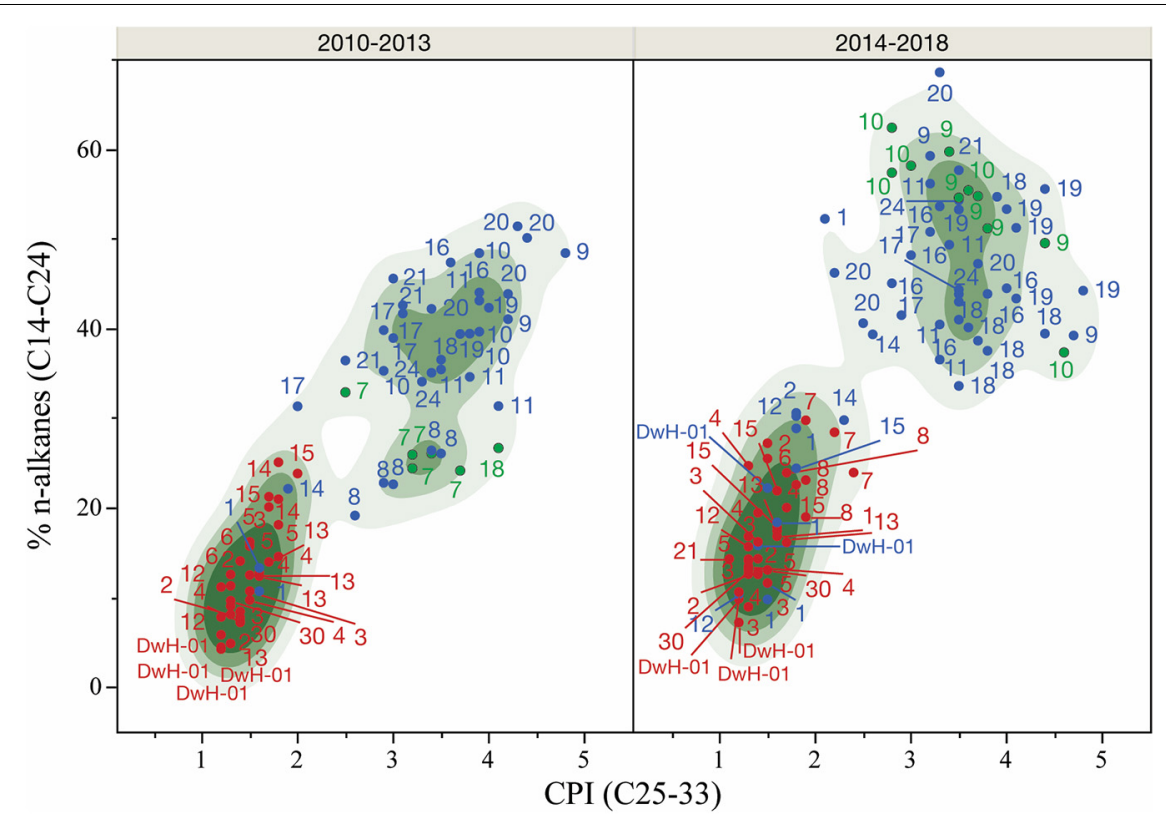

FIGURE 12 | Cross plots of diagnostic ratios for the deep-sea sites studied in the northern GoM. Numbers indicate sites, red circles denote sites with DwH oil-residues as the potential major source, green circles indicate sites with mixed hydrocarbons sources including DwH oil-residues, and blue circles indicate other unknown sources.

by episodic accumulation of sediments as being the main mechanism in sediment accumulation in this Region (Figure 2). Sedimentology reflects a dominance of fine-grained terrigenous source sediments with the highest \%silt in the study area. The source of pulsed sediments accumulating in Region 1 likely lay upslope to the $\mathrm{N}$ and NW. The first peak in particle resuspension over time with increasing flow speed occurred above $10 \mathrm{~cm}$ $\mathrm{s}^{-1}$ in this Region followed by a total collapse of the sediment structure and complete erosion occurred above $13 \mathrm{~cm} \mathrm{~s}^{-1}$. These high initial flow speeds needed to erode the surface indicate that this material was relatively new material that had arrived from the sea surface.

Region 2 is a transition zone from steep slopes $\left(>10^{\circ}\right)$ on the salt domes with deep incised smooth valleys between these domes (Figure 1) spreading out into an open plain on the seafloor with a decrease in slopes to near $0^{\circ}$ in the more distal, SE portions. Region 1 and Region 2 had similar surface sediment characteristics. The water depth in this Region ranges from 1,250 to $1,900 \mathrm{~m} .{ }^{210} \mathrm{~Pb}_{x s}$ data indicate more consistent stable accumulation with lower MAR's indicating that downslope sediment transport is not dominantly accumulating and is likely bypassing this Region (Figures $\mathbf{5 A - C}$ ). Evidence for sediment resuspension in this area by near inertial currents as well as tropical storm induced events has been reported in independent studies at these water depths (Gardner and Sullivan, 1981; Isley et al., 1990; Diercks et al., 2018), which may also limit deposition of sediments associated with down-slope transport. Sedimentology shows a decrease in \%terrigenous sediments as compared to Region 1, which is expected with increased distance from the Mississippi River. In this Region, peaks in volume of particles resuspended occurred at flow speeds above $13 \mathrm{~cm} \mathrm{~s}^{-1}$ indicating that the cores were missing the surface layer of loose material. These sites had the highest \%carbon and the most enriched $\Delta{ }^{14} \mathrm{C}$ values indicating deposition of younger material originating from the sea surface and not from resuspension.

The NW boundary of Region 3 can be visualized by a line drawn just north of sites 7, 12 and 15, with sites 12 and 15 being on the boundary between the two Regions (Figure 4). Region 3 encompasses the largest part of the study area on the seafloor with depths greater than 1,900 m. Most of the sites in Region 3 do not contain $\mathrm{DwH}$ oil-residues as the potential major source for hydrocarbons (eight out of eleven studied sites in this region). The majority of sites in Region 3 have higher relative abundance of $\mathrm{C} 12-\mathrm{C} 25 n$-alkanes in most sediment layers (Supplementary Figures 9a,b), indicating a potential larger presence of bacterial alkanes. Seafloor slope angles in this area are in general $<2^{0}$, sloping from the NW to the SE. Region 3 has the highest MAR's (Figures 5A-C and Supplementary Figure 3) and sediment records indicate a strong prevalence of episodic (pulses) sediment accumulation (Figure 4), likely associated with the down-slope transport events. The NE portion of Region 3 has the highest \%clay, which may indicate accumulation of resuspended fine-grained sediments from upslope. The highest \%sand values were found in the SE portion of Region 3 associated with more sand sized biogenic grains as shown by the concurrent increase in \%carbonate. This was likely due to a decrease in fine-grained terrigenous sediment with further distance from the Mississippi River source. The uppermost $2 \mathrm{~mm}$ of sediments from cores collected in this area were easily resuspended at current speeds of $5-8 \mathrm{~cm} \mathrm{~s}^{-1}$. Figure 3 indicating that these sediments consisted of unconsolidated material. \%Carbon content (Figure 6) for these samples were low (1.25 to 1.75\%), 

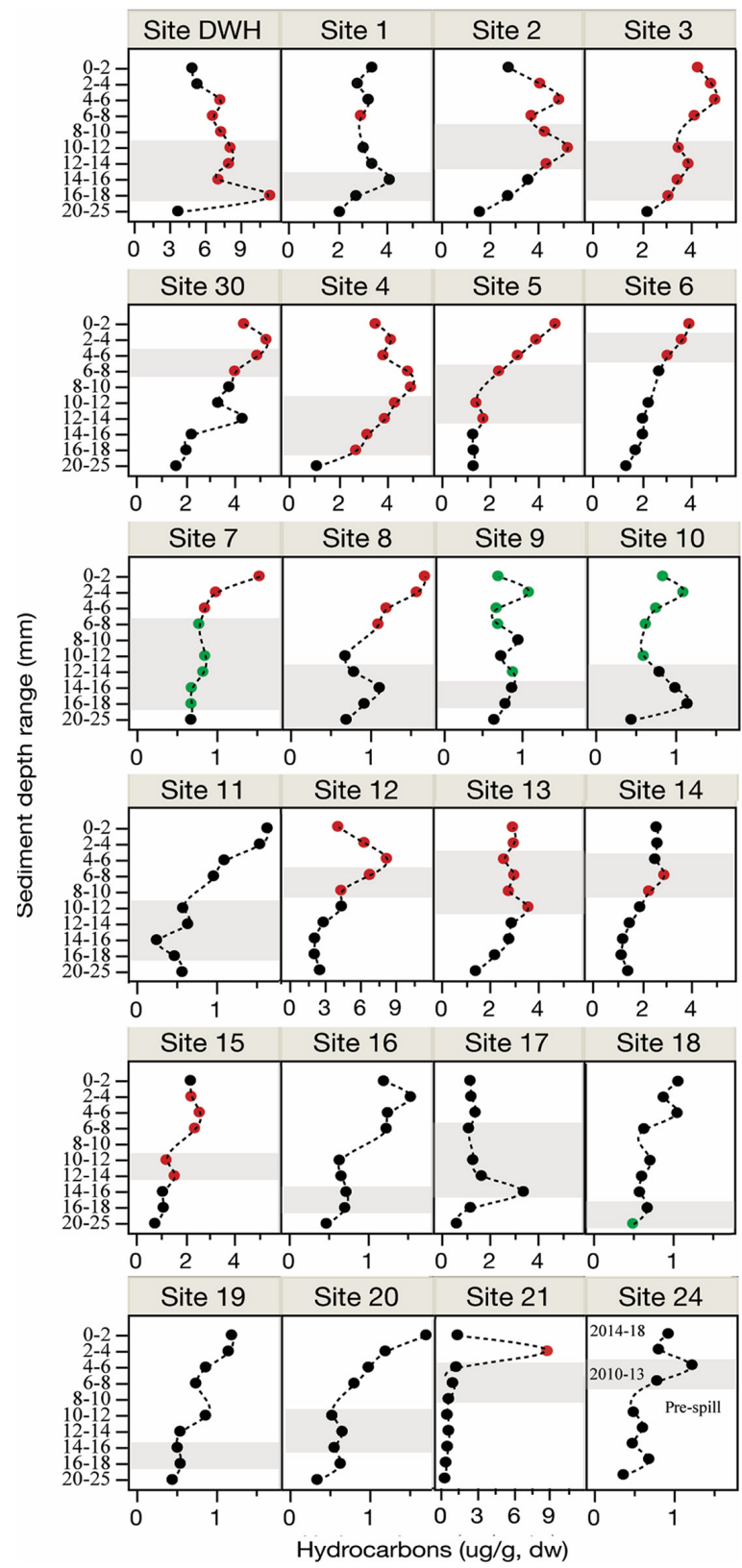

FIGURE 13 | Profiles of hydrocarbon concentrations in the study sites located in the northern GoM. Hydrocarbons refer to the sum of aliphatics, PAHs, hopanes, steranes, and TAS. Graph shows shaded areas corresponding to the time period 2010-2013, areas above and below the gray area corresponds to 2014-2018 and pre-spill periods, respectively. Red circles denote samples with DwH oil-residues as the potential major source, green circles indicate samples with mixed hydrocarbons sources including $\mathrm{DWH}$ oil-residues, and black circles indicate other unknown sources.

indicating older (Figure 8) reworked material being deposited, as discussed elsewhere (e.g., Diercks et al., 2018). We argue that these sediments either have been exposed to prolonged bacterial decomposition and remineralization after deposition on the seafloor or were transported from higher up on the slope as a result of resuspension and lateral transport. This lateral transport and redeposition of material would result in a loosely consolidated sediment layer, easier to be resuspended at lower flow speeds, and presenting the characteristics of an old sediment. This transport and redeposition of older material matches the results from the watershed model of the study area, which presented a general $\mathrm{E}$ to SE flow direction with a confluence of gravitational flow channels in the SE part of the Region (Figure 1). The model used the high-resolution seafloor morphology to determine gravity driven downslope flow and overlying water column currents were not considered.

Sedimentary structures indicative of sediment re-deposition by gravity flow processes were detected in almost all cores throughout the study area (Figure 2 and Table 1). Thin, mmscale, sub-parallel laminae and wavy-bedded units, by far the most common, were found in Regions 1, 2, and 3. The less common inclined beds and color banded units were confined to Regions 2 and 3 (Figure 4). All of these structures are common in adjacent Mississippi Fan deposits, and have been attributed to low density, fine-grained turbidity currents, slides and/or slumps (Coleman et al., 1986; Cremer and Stow, 1986; Normark et al., 1986; Stow et al., 1986; Thayer et al., 1986). Locations classified as depocenters exhibited two peaks in particle counts with increased flow speeds, one at low flow speeds and a second peak at higher flow speeds. This second peak coincided with the peaks from locations (erosional sites) that were missing the low flow speed peaks, indicating that the surface sediments in the depocenters were comprised of two distinctly different materials, loosely compacted material at the surface and a more consolidated layer of material below the surface. Once flow speeds in the flume reached $13 \mathrm{~cm} \mathrm{~s}^{-1}$ the exposed sediment in all cores eroded and disintegrated rapidly. Our results fall well within the range of prior data published in the literature. Lampitt (1985) reported that $6-8 \mathrm{~cm} \mathrm{~s}^{-1}$ can move low-density aggregates of phytodetritus ( $\mathrm{mm}$ to $\mathrm{cm}$ in size) in the field and similar values have been reported for flume studies. Beaulieu (2003) compiled a list of theoretical, flume, and field measurements for critical erosion velocities of bioturbated silty sediments, which (Gardner et al., 2017) further summarized and concluded that resuspension of the fine silt fraction would occur as low as $11-12 \mathrm{~cm} \mathrm{~s}^{-1}$ and sand size fraction being resuspended at 25$30 \mathrm{~cm} \mathrm{~s}^{-1}$.

Relative to levels of concern of toxic compounds analyzed in this study, we found that even though PAHs were abundant at the studied sites, most of their concentrations were lower than levels of concern for marine biota (Long et al., 1995; Bejarano and Michel, 2010) (Supplementary Figures 10a,b). Exceptions were found for LMW PAHs at site 1 (sediment interval 0$2 \mathrm{~mm}$ with concentration $0.6 \mu \mathrm{g} / \mathrm{g}$ ), and for HMW PAHs at site DwH (sediment interval 16-25 $\mathrm{mm}$ with concentrations about $2.6 \mu \mathrm{g} / \mathrm{g}$ ) and site 17 (sediment interval $16-18 \mathrm{~mm}$ with $2.6 \mu \mathrm{g} / \mathrm{g}$ concentration).

\section{Time Periods}

To better understand the role of major natural (e.g., downslope movement of particles) and anthropogenic (i.e., MOSSFA) depositional processes on the fate of $\mathrm{DwH}$-derived hydrocarbons 

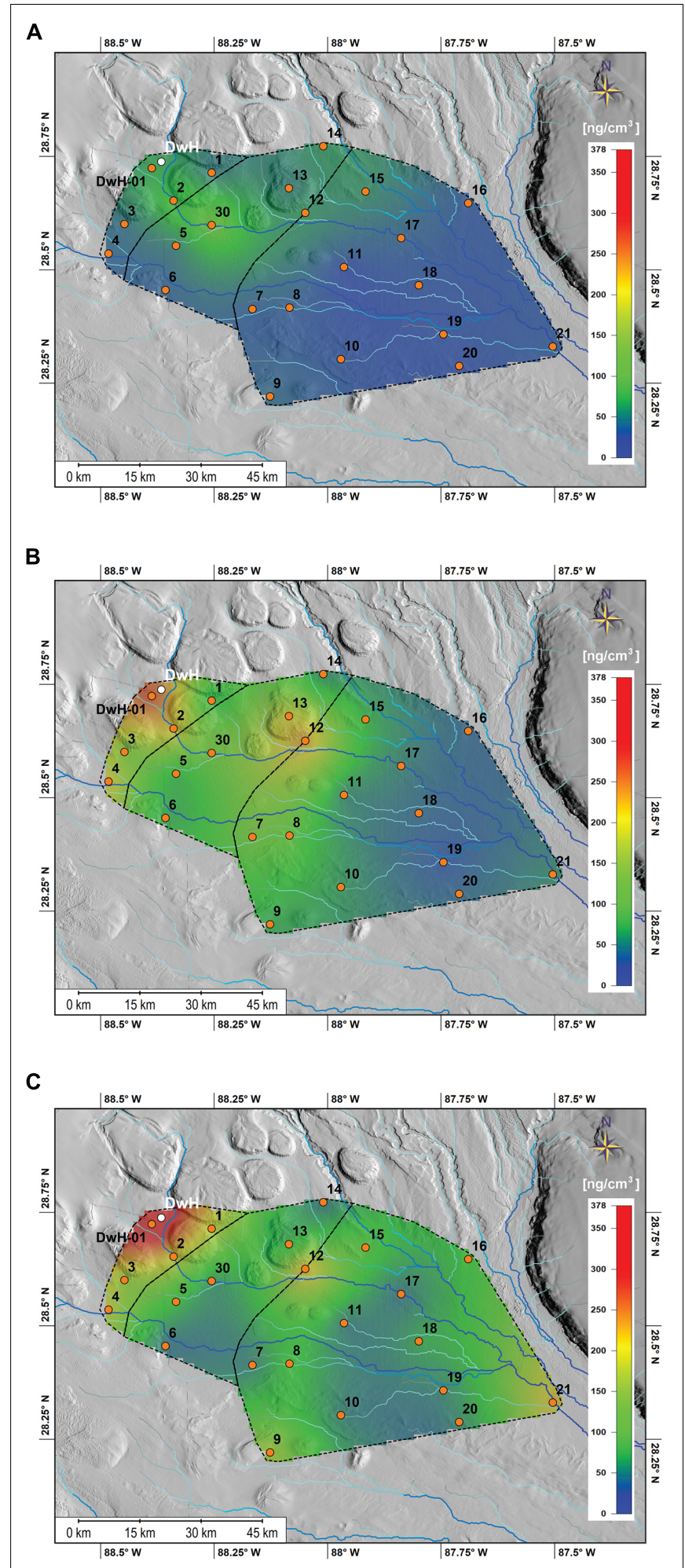

FIGURE 14 | Sediment depth-integrated biomarker concentrations in deep-sea sediments by time periods: (A) prespill (<2010), (B) spill/post-spill (2010-2013), (C) post-spill (2014-2018). Biomarker concentrations include the sum of hopanes (C23-C35), steranes (C27-C29), triaromatic steroids (C20-C21, C26-C28). Time periods were determined based on the established chronology. in deep-sea environments of the GoM, data were assessed for three time-periods (pre-spill 2006-2009, spill/post-spill 20102013, and post-spill 2014-2018). The pre-spill (2006-2009) time interval represents sediment data from before the $\mathrm{DwH}$ spill and MOSSFA event and is characterized by having lower concentrations of hydrocarbons compared to the other time periods (Figure 13). The 2010-2013 time interval, includes the time immediately after the oil spill as well as the MOSSFA event as defined by areas sampled during and immediately after the spill (Passow et al., 2012; Brooks et al., 2015; Daly et al., 2016; Larson et al., 2018). In this time period, eleven sites of the 24 studied sites likely contain $\mathrm{DwH}$ oil-residues as the potential major source for hydrocarbons (Figure 13). Most of the eleven sites containing DwH oil-residues are in the Region 1 and 2, and only one site in Region 3 (site 15). The 2014-2018 interval represents the time post MOSSFA event, in which we identified lateral and downslope movement of material into the deeper sections of the GoM. These time periods provided the basis to test our hypothesis of a general down-slope, SE transport of material that was initially deposited during the DwH oil spill. DwH oilresidues that were deposited under the surface expression of the oil spill and the submerged oil plumes, may have been moved downslope through common processes like resuspension and gravity flows (Diercks et al., 2018).

In the time period between 2014 and 2018, MARs had returned to pre-spill levels (Larson et al., 2018), however, there was large variability between the three time periods observed in total concentration of hydrocarbons (Figure 13), as well as for specific hydrocarbon compounds (Supplementary Figures 9a,b). This variability is highlighted by the relative composition among time-periods, which indicate a highly dynamic sedimentation regime in the study area (Supplementary Figures 5a,b). In this time period, 14 sites of the 24 studied sites contain $\mathrm{DwH}$ oil-residues as the potential major source for hydrocarbons (Figure 13). The 14 sites containing DwH oil-residues are located in all regions and only four sites $(\# 1,7,8,21)$ contain $\mathrm{DwH}$ oil-residues in the period 2014-2018 (Figure 13). Mapping the most recalcitrant compounds, such as biomarkers for each time period, presents the general spatial patterns of hydrocarbon concentrations decreasing toward the southeast of the study area (Figures 14A-C). Most elevated concentrations were observed only post-spill (2010-2013 and 2014-2018), mostly at sites located closer to the DwH site (Figures 14A-C). Millimeterscale events were identified within the upper two centimeters (Figure 13). These events were typically dated between 2014 and 2016 (post-DwH), are consistent with redeposition of resuspended material and were characterized by relatively high MAR, homogenous bulk organic $\delta^{13} \mathrm{C}$, and maxima in both organic biomarkers and benthic foraminifera fracture percentage. The uppermost $2 \mathrm{~mm}$ of the cores were dominated by benthic foraminifera (e.g., predominantly Bolivina lowmani, Eponides turgidus, Trochammina inflata, Uvigerina peregrina), planktic foraminifera (e.g., Globigerinoides ruber, Globorotalia menardii, Orbulina universa) and some deep-sea sediments and date to the 2016-2018 depositional period, providing an average sedimentation rate of 0.10 to $0.14 \mathrm{~g} \mathrm{~cm}^{3}$ year ${ }^{-1}$ as determined by MARs from ${ }^{210} \mathrm{~Pb}_{x s}$ measurements. 


\section{CONCLUSION}

Overall, our results indicate an increased spatial footprint of deposition of DwH-derived hydrocarbons for which we offer two explanations. The deposition of contaminated sediments was not previously identified due to a lack of sampling in our study area and down-slope redistribution of sediments over the 8 years following the DwH oil spill and initial MOSSFA deposition to the seafloor. We based our conclusions on the characteristics of three regions as defined by their morphological and sedimentological features as well as the likelihood of sediments accumulating in these regions through episodic down-slope transport mechanisms. The nature of the organic compounds found in some of the cores, as well as sediment composition from these regions allowed us to trace them back to the DwH oil spill (in 15 out of 24 studied sites). Region 1 showed the presence of episodic sediment accumulation and had a potential for longer term accumulation and sequestration of redistributed sediments from up-slope areas. Region 2 was defined by stable and consistent sediment accumulation with low magnitude events in down-slope sediment accumulation being very subtle in the sedimentary record. We determined that this area is less likely to accumulate and sequester redistributed sediments. Region 3 had an increased presence of episodic sediment accumulation through larger magnitude pulse events. These events lead to a higher potential for accumulation and sequestration of redistributed sediments from upslope areas.

Our findings presented in this paper, provide evidence that the footprint of the residues from the oil spill on the seafloor changed over the time span from 2010 to 2018 expanding to the SE beyond the previous areal extent reported. In the sedimentary record, $\mathrm{DwH}$ oil-residues were found in sites during the post-spill periods studied (20102013: during the MOSSFA event; 2014-2018: post MOSSFA event; sites: DwH-01, 2, 3, 4, 5, 6, 12, 13, 15, 30) as well as in sites only during the 2014-2018 period (sites: 1, 8, 21). Specifically, sites located approximately $45 \mathrm{~km}$ (site 8; $28.4166^{\circ} \mathrm{N}, 88.0838^{\circ} \mathrm{W}$ ) and $96 \mathrm{~km}$ (site $21 ; 28.3306^{\circ} \mathrm{N}$, $87.5042^{\circ} \mathrm{W}$ ) to the SE of the wellhead, indicate a larger area affected by $\mathrm{DwH}$ oil residues due only to down slope redistribution of organic matter by natural process at depth in the GoM. Our data thus suggest that a much larger area on the seafloor contained residues of DWH oil than previously then previously recognized and published in the literature (Lehr et al., 2010; Chanton et al., 2012; Lubchenco et al., 2012; Romero et al., 2017).

\section{REFERENCES}

Adhikari, P., Wong, R., and Overton, E. (2017). Application of enhanced gas chromatography/triple quadrupole mass spectrometry for monitoring petroleum weathering and forensic source fingerprinting in samples impacted by the deepwater horizon oil spill. Chemosphere 184, 939-950. doi: 10.1016/j. chemosphere.2017.06.077

\section{DATA AVAILABILITY STATEMENT}

The datasets presented in this study can be found in online repositories. The names of the repository/repositories and accession number(s) can be found below: Data are publicly available through the Gulf of Mexico Research Initiative Information \& Data Cooperative (GRIIDC) at https: //data.gulfresearchinitiative.org: doi: 10.7266/n7-5xgs-mg78; doi: 10.7266/n7-ry85-yq61; 10.7266/n7-gzhr-0s83; doi: 10.7266/n7zwvz-6a72; doi: 10.7266/n7-h6gj-1m18; doi: 10.7266/n7-391g9t63; doi: 10.7266/N7445K2V; doi: 10.7266/n7-6bfd-g305; and doi: $10.7266 /$ HCKBSN5J.

\section{AUTHOR CONTRIBUTIONS}

All authors listed have made a substantial, direct and intellectual contribution to the work, and approved it for publication.

\section{FUNDING}

The REDIRECT (Resuspension, Redistribution and Deposition of Deepwater Horizon recalcitrant hydrocarbons to offshore depocenter) research was made possible by a grant from The Gulf of Mexico Research Initiative (GOMRI). Also, research was supported by an Early-Career Research Fellowship from the Gulf Research Program of the National Academies of Sciences, Engineering, and Medicine to IC Romero (Grant \#2000010685). The content in this publication is solely the responsibility of the authors and does not necessarily represent the official views of the Gulf Research Program of the National Academies of Sciences, Engineering, and Medicine.

\section{ACKNOWLEDGMENTS}

The authors would like to thank the crew of the R/V Point Sur for their help during the field program and the technicians Hannah Hamontree, and Olivia Traenkle for laboratory support during chemical analyses of hydrocarbons.

\section{SUPPLEMENTARY MATERIAL}

The Supplementary Material for this article can be found online at: https://www.frontiersin.org/articles/10.3389/fmars. 2021.630183/full\#supplementary-material

Aeppli, C., Nelson, R. K., Radović, J. R., Carmichael, C. A., Valentine, D. L., and Reddy, C. M. (2014). Recalcitrance and degradation of petroleum biomarkers upon abiotic and biotic natural weathering of Deepwater Horizon oil. Environ. Sci. Technol. 48, 6726-6734. doi: 10.1021/es500825q

Appleby, P. G. (2001). "Chronostratigraphic techniques in recent sediments," in Tracking Environmental Change Using Lake Sediments: Basin Analysis, Coring, and Chronological Techniques Developments in Paleoenvironmental Research, 
eds W. M. Last and J. P. Smol (Dordrecht: Springer Netherlands), 171-203. doi: 10.1007/0-306-47669-x_9

Appleby, P. G., and Oldfield, F. (1983). The assessment of $210 \mathrm{~Pb}$ data from sites with varying sediment accumulation rates. Hydrobiologia 103, 29-35. doi: 10. 1007/BF00028424

Ash-Mor, A., Bookman, R., Kanari, M., Ben-Avraham, Z., and AlmogiLabin, A. (2017). Micropaleontological and taphonomic characteristics of mass transport deposits in the northern Gulf of Eilat/Aqaba, Red Sea. Mar. Geol. 391, 36-47. doi: 10.1016/j.margeo.2017. 07.009

Baskaran, M., Nix, J., Kuyper, C., and Karunakara, N. (2014). Problems with the dating of sediment core using excess $(210) \mathrm{Pb}$ in a freshwater system impacted by large scale watershed changes. J. Environ. Radioact. 138, 355-363. doi: 10. 1016/j.jenvrad.2014.07.006

Beaulieu, S. E. (2003). Resuspension of phytodetritus from the sea floor: a laboratory flume study. Limnol. Oceanogr. 48, 1235-1244. doi: 10.4319/lo.2003. 48.3.1235

Bejarano, A. C., and Michel, J. (2010). Large-scale risk assessment of polycyclic aromatic hydrocarbons in shoreline sediments from Saudi Arabia: environmental legacy after twelve years of the Gulf war oil spill. Environ. Pollut. 158, 1561-1569. doi: 10.1016/j.envpol.2009.12.019

Binford, M. W. (1990). Calculation and uncertainty analysis of $210 \mathrm{~Pb}$ dates for PIRLA project lake sediment cores. J. Paleolimnol. 3, 253-267. doi: 10.1007/ BF00219461

Borrowman, T. D., Smith, E. R., Gailani, J. A., and Caviness, L. (2006). Erodibility Study of Passaic River Sediments Using USACE Sedflume. Fort Belvoir, VA: Defense Technical Information Center.

Brady, H. B. (1878). On the reticularian and radiolarian rhizopoda (Foraminifera and Polycystina) of the North Polar Expedition of 1875-76. Ann. Mag. Nat. Hist. 5, 425-440. doi: 10.1080/00222937808682361

Brady, H. B. (1879). Notes on some of the reticularian Rhizopoda of the challenger expedition, part i. on new or little known arenaceous types. Q. J. Microsc. Sci. 19, 20-63. doi: 10.1242 jcs.s2-19.73.20

Brady, H. B. (1884). Report on the foraminifera dredged by H.M.S. Challenger during the years 1873-1876. Zoology 9, 1-814.

Brooks, G. R., Larson, R. A., Schwing, P. T., Romero, I., Moore, C., Reichart, G.-J., et al. (2015). Sedimentation pulse in the NE gulf of mexico following the 2010 DWH Blowout. PLoS One 10:e0132341. doi: 10.1371/journal.pone. 0132341

Camilli, R., Reddy, C. M., Yoerger, D. R., Van Mooy, B. A. S., Jakuba, M. V., Kinsey, J. C., et al. (2010). Tracking hydrocarbon plume transport and biodegradation at deepwater horizon. Science 330, 201-204. doi: 10.1126/science.11 95223

Chanton, J. P., Cherrier, J., Wilson, R. M., Sarkodee-Adoo, J., Bosman, S., Mickle, A., et al. (2012). Radiocarbon evidence that carbon from the Deepwater Horizon spill entered the planktonic food web of the Gulf of Mexico. Environ. Res. Lett. 7:045303. doi: 10.1088/1748-9326/7/4/045303

Chanton, J., Zhao, T., Rosenheim, B. E., Joye, S., Bosman, S., Brunner, C., et al. (2015). Using natural abundance radiocarbon to trace the flux of petrocarbon to the seafloor following the deepwater horizon oil spill. Environ. Sci. Technol. 49, 847-854. doi: 10.1021/es5046524

Choi, M., Kim, Y.-J., Lee, I.-S., and Choi, H.-G. (2014). Development of a one-step integrated pressurized liquid extraction and cleanup method for determining polycyclic aromatic hydrocarbons in marine sediments. J. Chromatogr. A 1340, 8-14. doi: 10.1016/j.chroma.2014.03.015

Choi, Y., and Wang, Y. (2004). Dynamics of carbon sequestration in a coastal wetland using radiocarbon measurements. Glob. Biogeochem. Cycles 18:GB4016. doi: 10.1029/2004GB002261

Coleman, J. M., Bouma, A. H., Roberts, H. H., and Thayer, P. A. (1986). "Stratification in mississippi fan cores revealed by X-Ray radiography," in Initial Reports of the Deep Sea Drilling Project, Vol. 96, eds A. H. Bouma, J. M. Coleman, and A. W. Meyer (Washington, D.C: U.S. Government Printing Office), 505-518.

Cremer, M., and Stow, D. A. V. (1986). Sedimentary structures of fine-grained sediments from the Mississippi Fan: Thin Section Analysis. Initial Reports of the Deep Sea Drilling Project. XCVI., 96, 519-532. http://deepseadrilling.org/96/ volume/dsdp96_24.pdf
Crowsey, R. C. (2013). Persistence of gulf of mexico surface oil from the 2010 deepwater horizon spill. Southeast. Geogr. 53, 359-361. doi: 10.1353/sgo.2013. 0034

Cushman, J. A. (1922). Shallow-Water Foraminifera of the Tortugas Region. Carnegie Inst. Wash. 17, 1-85.

Cushman, J. A. (1923). The foraminifera of the Atlantic Ocean. Part 4. Lagenidae. Bull. U.S. Natl. Mus. 104, 1-228. doi: 10.2113/49.suppl_2.1

Cushman, J. A. (1927). New and interesting foraminifera from Mexico and Texas. Contributions Cushman Lab. Foraminifer. Res. 3, 111-117.

d'Orbigny, A. D. (1826). Tableau méthodique de la classe des Céphalopodes. Ann. Sci. Nat. 7, 245-314.

d'Orbigny, A. D. (1839). Voyage dans l'Amerique Meridionale. Paris and Strasbourg: Bertrand, 1-86.

Daly, K. L., Passow, U., Chanton, J., and Hollander, D. (2016). Assessing the impacts of oil-associated marine snow formation and sedimentation during and after the Deepwater Horizon oil spill. Anthropocene 13, 18-33. doi: 10.1016/j. ancene.2016.01.006

Daly, K. L., Vaz, A. C., and Paris, C. B. B. (2020). The Sedimentation and Lateral Transport of Oil-Associated Marine Snow During and After the Deepwater Horizon Oil Spill. in (AGU). doi: 10.1007/978-3-030-12963-7_18

Dean, W. E. (1974). Determination of carbonate and organic matter in calcareous sediments and sedimentary rocks by loss on ignition; comparison with other methods. J. Sediment. Res. 44, 242-248. doi: 10.1306/74D729D2-2B21-11D78648000102C1865D

Diercks, A.-R., Dike, C., Asper, V. L., DiMarco, S. F., Chanton, J. P., and Passow, U. (2018). Scales of seafloor sediment resuspension in the northern Gulf of Mexico. Elem. Sci. Anth. 6:32. doi: 10.1525/elementa.285

Diercks, A.-R., Highsmith, R. C., Asper, V. L., Joung, D., Zhou, Z., Guo, L., et al. (2010). Characterization of subsurface polycyclic aromatic hydrocarbons at the Deepwater Horizon site. Geophys. Res. Lett. 37:L20602. doi: 10.1029/ 2010GL045046

Folk, R. L. (1965). Petrology of Sedimentary Rocks. Austin, TX: Hemphill.

Gardner, W. D., and Sullivan, L. G. (1981). Benthic storms: temporal variability in a deep-ocean nepheloid layer. Science 213, 329-331. doi: 10.1126/science.213. 4505.329

Gardner, W. D., Tucholke, B. E., Richardson, M. J., and Biscaye, P. E. (2017). Benthic storms, nepheloid layers, and linkage with upper ocean dynamics in the western North Atlantic. Mar. Geol. 385, 304-327. doi: 10.1016/j.margeo.2016. 12.012

Gros, J., Reddy, C. M., Aeppli, C., Nelson, R. K., Carmichael, C. A., and Arey, J. S. (2014). Resolving biodegradation patterns of persistent saturated hydrocarbons in weathered oil samples from the Deepwater Horizon disaster. Environ. Sci. Technol. 48, 1628-1637. doi: 10.1021/es4042836

Herrera-Herrera, A. V., Leierer, L., Jambrina-enríquez, M., Connolly, R., and Mallol, C. (2020). Evaluating different methods for calculating the Carbon Preference Index (CPI): implications for palaeoecological and archaeological research. Org. Geochem. 146:104056. doi: 10.1016/j.orggeochem.2020.104056

Isley, A. E., Dale Pillsbury, R., and Laine, E. P. (1990). The genesis and character of benthic turbid events, Northern Hatteras Abyssal plain. Deep Sea Res. A Oceanogr. Res. Pap. 37, 1099-1119. doi: 10.1016/0198-0149(90)90053-X

Jernelöv, A., and Lindén, O. (1981). Ixtoc I: a case study of the world's largest oil spill. Ambio 10:299.

Jones, J. P., and Parker, W. K. (1860). On the rhizopodal fauna of the mediterranean compared with that of the Italian and some other tertiary deposits. Q. J. Geol. Soc. Lond. 16, 292-307. doi: 10.1144/gsl.jgs.1860.016.01-02.41

Joye, S. B., Crespo-Medina, M., Hunter, K., Asper, V., Diercks, A., Passow, U., et al. (2013). Increased sedimentation and altered nutrient cycling in the aftermath of the Macondo oil well blowout. Abstr. Pap. Am. Chem. Soc. 245.

Kim, J. H., Moon, J. K., Li, Q. X., and Cho, J. Y. (2003). One-step pressurized liquid extraction method for the analysis of polycyclic aromatic hydrocarbons. Anal. Chim. Acta 498, 55-60. doi: 10.1016/j.aca.2003.08.049

Kitto, M. E. (1991). Determination of photon self-absorption corrections for soil samples. Int. J. Radiat. Appl. Instrum. A 42, 835-839. doi: 10.1016/08832889(91)90221-L

Kramer, K. V., and Shedd, B. (2017). A 1.4-Billion-Pixel Map of the Gulf of Mexico Seafloor. Eos. Available online at: https://eos.org/project-updates/a-1-4-billionpixel-map-of-the-gulf-of-mexico-seafloor (Accessed January 11, 2018). 
Lampitt, R. S. (1985). Evidence for the seasonal deposition of detritus to the deepsea floor and its subsequent resuspension. Deep Sea Res. A Oceanogr. Res. Pap. 32, 885-897. doi: 10.1016/0198-0149(85)90034-2

Larson, R. A., Brooks, G. R., Schwing, P. T., Holmes, C. W., Carter, S. R., and Hollander, D. J. (2018). High-resolution investigation of event driven sedimentation: Northeastern Gulf of Mexico. Anthropocene 24, 40-50. doi: 10.1016/j.ancene.2018.11.002

Lehr, B., Bristol, S., and Possolo, A. (2010). Oil Budget Calculator Deepwater Horizon, A Report to the National Incident Command. https: //www.restorethegulf.gov/sites/default/files/documents/pdf/OilBudgetCalc_ Full_HQ-Print_111110.pdf

Long, E. R., Macdonald, D. D., Smith, S. L., and Calder, F. D. (1995). Incidence of adverse biological effects within ranges of chemical concentrations in marine and estuarine sediments. Environ. Manag. 19, 81-97. doi: 10.1007/BF02472006

Lubchenco, J., McNutt, M. K., Dreyfus, G., Murawski, S. A., Kennedy, D. M., Anastas, P. T., et al. (2012). Science in support of the Deepwater Horizon response. Proc. Natl. Acad. Sci. U.S.A. 109, 20212-20221. doi: 10.1073/pnas. 1204729109

Meyer, B. M., Adhikari, P. L., Olson, G. M., Overton, E. B., and Miles, M. S. (2017). Louisiana Coastal Marsh Environments and MC252 Oil Biomarker Chemistry. Amsterdam: Elsevier Inc.

Milliman, J. D. (1974). Marine carbonates. recent sedimentary carbonates part 1. Springer-Verlag, New York, Heidelberg, \& Berlin, $\mathrm{xv}+375$ p. \$25.50. Limno. Oceanogr. 19:876. doi: 10.4319/lo.1974.19.5.0876b

Mulabagal, V., Yin, F., John, G. F., Hayworth, J. S., and Clement, T. P. (2013). Chemical fingerprinting of petroleum biomarkers in Deepwater Horizon oil spill samples collected from Alabama shoreline. Mar Pollut Bull 70, 147-154. doi: 10.1016/j.marpolbul.2013.02.026

Normark, W. R., Meyer, A. W., Cremer, M., Droz, L., O'Connell, S., Pickering, K. T., et al. (1986). "Summary of drilling results for the Mississippi Fan and considerations for applications to other turbidite systems," in Initial Reports of the Deep Sea Drilling Project, eds A. H. Bouma, J. M. Coleman, and A. W. Meyer (Washington, DC: U.S. Government Printing Office), $425-436$.

Osterman, L. E. (2003). Benthic foraminifers from the continental shelf and slope of the Gulf of Mexico: an indicator of shelf hypoxia. Estuar. Coast. Shelf Sci. 58, 17-35. doi: 10.1016/S0272-7714(02)00352-9

Parker, F. L. (1954). Distribution of foraminifera in the Northeastern Gulf of Mexico. Bull. Mus. Comp. Zool. 111, 453-588.

Parker, F. L., Phleger, F. B., and Pierson, J. F. (1953). North Atlantic foraminifera. Rep. Swedish Deep Sea Expedition, 1947-1948 7, 3-122.

Parker, W. K., and Jones, T. R. (1865). On some foraminifera from the coast of Norway. Ann. Mag. Nat. Hist. 155, 325-441.

Passow, U., Chanton, J. P., Hollander, D., and Dahly, K. (2013). MOSSFA (Marine Oil Snow Sedimentation and Flocculent Accumulation) Working Group. Tallahassee, FL: Florida State University.

Passow, U., Ziervogel, K., Asper, V., and Diercks, A. (2012). Marine snow formation in the aftermath of the deepwater horizon oil spill in the Gulf of Mexico. Environ. Res. Lett. 7:035301. doi: 10.1088/1748-9326/7/3/035301

Patterson, R. T., and Fishbein, E. (1989). Re-examination of the statistical methods used to determine the number of point counts needed for micropaleontological quantitative research. J. Paleontol. 63, 245-248. doi: 10. 1017/S0022336000019272

Phleger, F. B., and Parker, F. L. (1951). Gulf of mexico foraminifera, Part 1 and 2. Geol. Soc. Am. Mem. 46.

Prince, R. C., Owens, E. H., and Sergy, G. A. (2002). Weathering of an Arctic oil spill over 20 years: the BIOS experiment revisited. Mar. Pollut. Bull. 44, 1236-1242. doi: $10.1016 / \mathrm{s} 0025-326 \mathrm{x}(02) 00214-\mathrm{x}$

Ramdahl, T. (1983). Retene-a molecular marker of wood combustion in ambient air. Nature 306, 580-582. https://doi.org/10.1038/306580a0

Romero, I. C., Chanton, J. P., Brooks, J. R., Bosman, S., Larson, R. A., Harris, A., et al. (2021). Molecular markers of biogenic and oil-derived hydrocarbons in deep-sea sediments following the Deepwater Horizon spill. Front. Mar. Sci. (in press). doi: 10.3389/fmars.2021.637970

Romero, I. C., Schwing, P. T., Brooks, G. R., Larson, R. A., Hastings, D. W., Ellis, G., et al. (2015). Hydrocarbons in deep-sea sediments following the 2010 deepwater horizon blowout in the Northeast Gulf of Mexico. PLoS One 10:e0128371. doi: 10.1371/journal.pone.0128371
Romero, I. C., Sutton, T., Carr, B., Quintana-Rizzo, E., Ross, S. W., Hollander, D. J., et al. (2018). Decadal Assessment of polycyclic aromatic hydrocarbons in mesopelagic fishes from the gulf of mexico reveals exposure to oil-derived sources. Environ. Sci. Technol. 52, 10985-10996. doi: 10.1021/acs.est.8b0 2243

Romero, I. C., Toro-Farmer, G., Diercks, A.-R., Schwing, P., Muller-Karger, F., Murawski, S., et al. (2017). Large-scale deposition of weathered oil in the Gulf of Mexico following a deep-water oil spill. Environ. Pollut. 228, 179-189. doi: 10.1016/j.envpol.2017.05.019

Schwing, P. T., Brooks, G. R., Larson, R. A., Holmes, C. W., O’Malley, B. J., and Hollander, D. J. (2017). Constraining the spatial extent of marine oil snow sedimentation and flocculent accumulation following the deepwater horizon event using an excess $210 \mathrm{~Pb}$ flux approach. Environ. Sci. Technol. 51, 59625968. doi: 10.1021/acs.est.7b00450

Schwing, P. T., O’Malley, B. J., and Hollander, D. J. (2018). Resilience of benthic foraminifera in the Northern Gulf of Mexico following the Deepwater Horizon event (2011-2015). Ecol. Indic. 84, 753-764. doi: 10.1016/j.ecolind.2017. 09.044

Schwing, P. T., Romero, I. C., Larson, R. A., O’Malley, B. J., Fridrik, E. E., Goddard, E. A., et al. (2016). Sediment core extrusion method at millimeter resolution using a calibrated, threaded-rod. J. Vis. Exp. 114, 54363. doi: 10.3791/ 54363

Smith, L. M., Alexander, C., and Jennings, A. E. (2002). Accumulation in east greenland fjords and on the continental shelves adjacent to the denmark strait over the last century based on $210 \mathrm{~Pb}$ geochronology. ARCTIC 55, 109-122. doi: $10.14430 /$ arctic695

Sørensen, L., Meier, S., and Mjøs, S. A. (2016). Application of gas chromatography/tandem mass spectrometry to determine a wide range of petrogenic alkylated polycyclic aromatic hydrocarbons in biotic samples. Rapid Commun. Mass Spectrom. 30, 2052-2058. doi: 10.1002/rcm.7688

Stewart, R. E., and Stewart, K. C. (1930). Post-miocene foraminifera from the ventura quadrangle, ventura county, California. J. Paleontol. 4, 60-72.

Stout, S. A., Payne, J. R., Ricker, R. W., Baker, G., and Lewis, C. (2016). Macondo oil in deep-sea sediments: part $2-$ distribution and distinction from background and natural oil seeps. Mar. Pollut. Bull. 111, 381-401. doi: 10.1016/j.marpolbul. 2016.07.041

Stow, D. A. V., Cremer, M., Droz, L., Meyer, A. W., Normark, W. R., O'Connell, S., et al. (1986). "Facies, composition, and texture of Mississippi Fan sediments, Deep Sea Drilling Project Leg 96, Gulf of Mexico," in Initial Reports of the Deep Sea Drilling Project, eds A. H. Bouma, J. M. Coleman, and A. W. Meyer (Washington, DC: U.S. Government Printing Office), 475-488.

Stuiver, M., and Polach, H. A. (1977). Discussion reporting of 14 C Data. Radiocarbon 19, 355-363. doi: 10.1017/S0033822200003672

Swarzenski, P. W. (2014). "210Pb dating," in Encyclopedia of scientific dating methods, eds W. J. Rink and J. Thompson (Dordrecht: Springer Netherlands), 1-11. doi: 10.1007/978-94-007-6326-5_236-1

Thayer, P., Roberts, H. H., Bouma, A. H., and Coleman, J. M. (1986). "Sedimentology and petrology of mississippi fan depositional environments, deep sea drilling project leg 96," in Initial Reports of the Deep Sea Drilling Project, eds A. H. Bouma, J. M. Coleman, and A. W. Meyer (Washington, D.C: U.S. Government Printing Office), 489-504.

Tobiszewski, M., and Namieśnik, J. (2012). PAH diagnostic ratios for the identification of pollution emission sources. Environ. Pollut. 162, 110-119. doi: 10.1016/j.envpol.2011.10.02

Turnewitsch, R., Dale, A., Lahajnar, N., Lampitt, R. S., and Sakamoto, K. (2017). Can neap-spring tidal cycles modulate biogeochemical fluxes in the abyssal near-seafloor water column? Prog. Oceanogr. 154, 1-24. doi: 10.1016/j.pocean. 2017.04.006

Turnewitsch, R., Falahat, S., Nycander, J., Dale, A., Scott, R. B., and Furnival, D. (2013). Deep-sea fluid and sediment dynamics-influence of hill- to seamountscale seafloor topography. Earth Sci. Rev. 127, 203-241. doi: 10.1016/j.earscirev. 2013.10.005

Turnewitsch, R., Reyss, J.-L., Chapman, D. C., Thomson, J., and Lampitt, R. S. (2004). Evidence for a sedimentary fingerprint of an asymmetric flow field surrounding a short seamount. Earth Planet. Sci. Lett. 222, 1023-1036. doi: 10.1016/j.epsl.2004.03.042

Valentine, D. L., Fisher, G. B., Bagby, S. C., Nelson, R. K., Reddy, C. M., Sylva, S. P., et al. (2014). Fallout plume of submerged oil from Deepwater Horizon. 
Proc. Natl. Acad. Sci. U.S.A. 111, 15906-15911. doi: 10.1073/pnas.141487 3111

Vogel, J. S., Southon, J. R., Nelson, D. E., and Brown, T. A. (1984). Performance of catalytically condensed carbon for use in accelerator mass spectrometry. Nuclear Instruments and Methods in Physics Research Section B: Beam Interactions with Materials and Atoms, 5, 289-293. https://doi.org/10.1016/ 0168-583X(84)90529-9

Wang, Z., and Fingas M. F. (2003). Development of oil hydrocarbon fingerprinting and identification techniques. Mar Pollut Bull 47, 423-452. doi: 10.1016/S0025326X(03)00215-7

Wang, Z., Fingas, M., Shu, Y. Y., Sigouin, L., Landriault, M., Lambert, P., et al. (1999). Quantitative Characterization of PAHs in Burn Residue and Soot Samples and Differentiation of Pyrogenic PAHs from Petrogenic PAHs-The 1994 Mobile Burn Study. Environ. Sci. Technol. 33, 3100-3109. doi: 10.1021/ es990031y

Wang, Z., Stout, S. A., and Fingas, M. (2006). Forensic Fingerprinting of Biomarkers for Oil Spill Characterization and Source Identification. Environ. Forensics 7, 105-146. doi: 10.1080/1527592060066 7104

Wang, Z. D., Fingas, M., Owens, E. H., Sigouin, L., and Brown, C. E. (2001). Long-term fate and persistence of the spilled Metula oil in a marine salt marsh environment - degradation of petroleum biomarkers. J. Chromatogr. A 926, 275-290. doi: 10.1016/s0021-9673(01)01051-2

White, H. K., Wang, C. H., Williams, P. L., Findley, D. M., Thurston, A. M., Simister, R. L., et al. (2016). Long-term weathering and continued oxidation of oil residues from the Deepwater Horizon spill. Mar. Pollut. Bull. 113, 380-386. doi: 10.1016/j.marpolbul.2016.10.02
Williamson, W. C. (1858). On the Recent Foraminifera of Great Britain. Ray Society, 1-107. https://doi.org/10.5962/bhl.title.139719

Xing, L., Zhang, H., Yuan, Z., Sun, Y., and Zhao, M. (2011). Terrestrial and marine biomarker estimates of organic matter sources and distributions in surface sediments from the East China Sea shelf. Cont. Shelf Res. 31, 1106-1115. doi: 10.1016/j.csr.2011.04.003

Yan, B., Passow, U., Chanton, J. P., Nöthig, E.-M., Asper, V., Sweet, J., et al. (2016). Sustained deposition of contaminants from the Deepwater Horizon spill. Proc. Natl. Acad. Sci. U.S.A. 113, E3332-E3340. doi: 10.1073/pnas.1513 156113

Ziervogel, K., Dike, C., Asper, V., Montoya, J., Battles, J., D×souza, N., et al. (2016). Enhanced particle fluxes and heterotrophic bacterial activities in Gulf of Mexico bottom waters following storm-induced sediment resuspension. Deep Sea Res. II Top. Stud. Oceanogr. 129, 77-88. doi: 10.1016/j.dsr2.2015 .06 .017

Conflict of Interest: The authors declare that the research was conducted in the absence of any commercial or financial relationships that could be construed as a potential conflict of interest.

Copyright (c) 2021 Diercks, Romero, Larson, Schwing, Harris, Bosman, Chanton and Brooks. This is an open-access article distributed under the terms of the Creative Commons Attribution License (CC BY). The use, distribution or reproduction in other forums is permitted, provided the original author(s) and the copyright owner(s) are credited and that the original publication in this journal is cited, in accordance with accepted academic practice. No use, distribution or reproduction is permitted which does not comply with these terms. 